\title{
Projected sea level rise and changes in extreme storm surge and wave events during the 21st century in the region of Singapore
}

\author{
Heather Cannaby ${ }^{1}$, Matthew D. Palmer ${ }^{2}$, Tom Howard ${ }^{2}$, Lucy Bricheno ${ }^{1}$, Daley Calvert ${ }^{2}$, Justin Krijnen ${ }^{2}$, \\ Richard Wood ${ }^{2}$, Jonathan Tinker ${ }^{2}$, Chris Bunney ${ }^{2}$, James Harle $^{1}$, Andrew Saulter ${ }^{2}$, Clare O’Neill ${ }^{2}$, \\ Clare Bellingham ${ }^{1}$, and Jason Lowe ${ }^{2}$ \\ ${ }^{1}$ National Oceanography Centre, 6 Brownlow Street, Liverpool, L3 5DA, UK \\ ${ }^{2}$ Met Office, Fitz Roy Road, Exeter, Devon, EX1 3PB, UK \\ Correspondence to: Heather Cannaby (heanna@noc.ac.uk)
}

Received: 5 November 2015 - Published in Ocean Sci. Discuss.: 4 December 2015

Revised: 26 February 2016 - Accepted: 16 March 2016 - Published: 2 May 2016

\begin{abstract}
Singapore is an island state with considerable population, industries, commerce and transport located in coastal areas at elevations less than $2 \mathrm{~m}$ making it vulnerable to sea level rise. Mitigation against future inundation events requires a quantitative assessment of risk. To address this need, regional projections of changes in (i) long-term mean sea level and (ii) the frequency of extreme storm surge and wave events have been combined to explore potential changes to coastal flood risk over the 21 st century. Local changes in time-mean sea level were evaluated using the process-based climate model data and methods presented in the United $\mathrm{Na}$ tions Intergovernmental Panel on Climate Change Fifth Assessment Report (IPCC AR5). Regional surge and wave solutions extending from 1980 to 2100 were generated using $\sim 12 \mathrm{~km}$ resolution surge (Nucleus for European Modelling of the Ocean - NEMO) and wave (WaveWatchIII) models. Ocean simulations were forced by output from a selection of four downscaled ( $\sim 12 \mathrm{~km}$ resolution) atmospheric models, forced at the lateral boundaries by global climate model simulations generated for the IPCC AR5. Long-term trends in skew surge and significant wave height were then assessed using a generalised extreme value model, fit to the largest modelled events each year. An additional atmospheric solution downscaled from the ERA-Interim global reanalysis was used to force historical ocean model simulations extending from 1980 to 2010, enabling a quantitative assessment of model skill. Simulated historical sea-surface height and significant wave height time series were compared to tide gauge data and satellite altimetry data, respectively. Central estimates of the long-term mean sea level rise at Singapore by
\end{abstract}

2100 were projected to be $0.52 \mathrm{~m}(0.74 \mathrm{~m})$ under the Representative Concentration Pathway (RCP)4.5 (8.5) scenarios. Trends in surge and significant wave height 2 -year return levels were found to be statistically insignificant and/or physically very small under the more severe RCP8.5 scenario. We conclude that changes to long-term mean sea level constitute the dominant signal of change to the projected inundation risk for Singapore during the 21 st century. We note that the largest recorded surge residual in the Singapore Strait of $\sim 84 \mathrm{~cm}$ lies between the central and upper estimates of sea level rise by 2100 , highlighting the vulnerability of the region.

\section{Introduction}

Singapore is an island state with considerable population, industries, commerce and transport located in coastal areas at elevations less than $2 \mathrm{~m}$ (Wong, 1992). Singapore is thus potentially exposed to the effects of sea level rise and climate induced changes in extreme events. Mitigation against future inundation events requires a quantitative assessment of risk. Global-scale climate projections generated for the Intergovernmental Panel on Climate Change Assessment Reports (Meehl et al., 2007; Church et al., 2013) are generally on too coarse a grid scale to provide relevant information at the regional scale (e.g. Allen et al., 2010; Penduff et al., 2010). Hence, the assessment of climate change impacts on regional coastlines requires a focused regional study. To address this need, regional projections of changes in (i) long- 


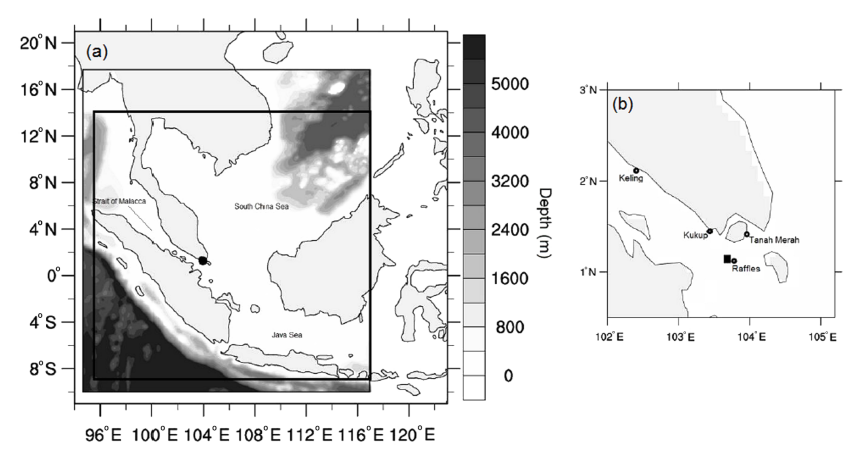

Figure 1. (a) Bathymetric map showing the location of Singapore (black circle) in relation to the climate model domain (outermost square), the surge model domain (shaded depth contours), and the wave model domain (innermost square). (b) Map of Singapore showing the location of tide gauge metres utilised for model validation, and showing the location of grid point "a" as referred to in the results section (black rectangle).

term mean sea level and (ii) the frequency of extreme storm surge and wave events have been combined to explore potential changes to coastal flood risk in Singapore over the 21st century. The following paragraphs briefly summarise the processes that influence temporal variability in sea level in the Singapore Strait.

Located in the middle of the Sunda shelf, the Singapore Strait (Fig. 1a) is connected via the South China Sea to the Pacific Ocean in the northeast, to the Java Sea in the southeast, and via the Malacca Strait to the Indian Ocean in the west. Regional tides are complex with several amphidromic points located in the South China Sea. Tides propagate into the Singapore Strait via the Malacca Strait and from the open seas to the east, resulting in a complex mix of diurnal and semi-diurnal tides observed around the coastline of Singapore (Maren and Gerritsen, 2012). The mean tidal range at Singapore is $\sim 2 \mathrm{~m}$ and the spring maximum range is $\sim 3 \mathrm{~m}$.

The weather in Singapore is influenced by the Northern Hemisphere and Southern Hemisphere monsoon systems. Winds are from the north and northeast during the northeast monsoon season, which extends from December to early March and from the south or southeast during the southwest monsoon season, which extends from June to September. In response to the monsoon winds, the sea level in the Singapore Strait exhibits seasonal variability of the order of $\pm 20 \mathrm{~cm}$, being the highest during the northeast monsoon when the fetch is greatest. Extreme sea level anomaly events in Singapore tend to coincide with prolonged (lasting for several days in duration) northeast winds over the South China Sea during this season (e.g. Tkalich et al., 2009). Interannual variability in sea level is dominated by El Niño and La Niña events, which cause the sea-surface height (SSH) to vary by $\pm 5 \mathrm{~cm}$, with lower SSH observed during El Niño events (Tkalich et al., 2013).
The sheltered location of Singapore results in significant wave heights that are typically less than $1 \mathrm{~m}$. Waves of close to $1 \mathrm{~m}$ in height occur along the southwest coast during squall events associated with the southwest monsoon. However, extreme wave events occurring during the northwest monsoon have the potential to be more damaging due to the higher sea level during this season.

Tkalich et al. (2013) reported that sea level in the Singapore strait has been rising at an average rate of 1.2$1.7 \mathrm{~mm} \mathrm{yr}^{-1}$ between 1975 and 2009, $1.8-2.3 \mathrm{~mm} \mathrm{yr}^{-1}$ between 1984 and 2009 and $1.9-4.5 \mathrm{~mm} \mathrm{yr}^{-1}$ between 1996 and 2009. The trend is larger than the global mean during the earlier period and smaller during the latter period. Over multi-decadal timescales, accounting for glacial isostatic adjustment, sea level in the Singapore Strait has been rising at approximately the same rate as the global mean. Bird et al. (2010) considered the impact of pre-observational (early Holocene) sea level change on human dispersal in coastal regions of Singapore, and provide evidence of the rapid rate at which regional sea levels changed during this period. The authors suggest sea levels rose at a rate of $1.8{\mathrm{~m} 100 \mathrm{yr}^{-1}}^{-1}$ between 8900 and $8100 \mathrm{cal} \mathrm{BP}$, exhibited little change in between 7800 and $7400 \mathrm{cal} \mathrm{BP}$ and then a rose by $4-5 \mathrm{~m}$ by 6500 cal BP.

\section{Methods}

Change in the long-term climate of extreme sea level can arise due to (i) change in regional time-mean relative sea level and (ii) change in the frequency/intensity of extreme events. There is evidence from dynamical modelling studies based in the North Sea (e.g. Howard et al., 2010; Sterl et al., 2009) and the Gulf of Mexico (e.g. Smith et al., 2010) that these two components of change can be modelled separately and then combined linearly to give a total projected extreme sea level change. This is the approach taken in this study, although we note that this finding is not necessarily applicable to all locations (e.g. Mousavi et al., 2011; Smith et al., 2010).

In this study climate projections are generated for two Representative Concentration Pathways (RCPs; Meinshausen et al., 2011), these being RCP4.5 and RCP8.5. The United Nations Intergovernmental Panel on Climate Change (IPCC) describe RCP4.5 as an intermediate emissions scenario and it was chosen to provide a moderate mitigation policy scenario. RCP4.5 is comparable to the Special Report on Emissions Scenarios (SRES) scenario B1, used in the United Nations Intergovernmental Panel on Climate Change Fourth Assessment Report (IPCC AR4) and is consistent with a future with relatively ambitious emissions reductions. RCP8.5 is described as a high emissions scenario and is consistent with a future with no policy changes to reduce emissions. RCP8.5 was chosen to provide an upper estimate of expected change (Meinshausen et al., 2011). 


\subsection{Calculation of local changes in time-mean sea level}

Projections of global mean sea level (GMSL) rise have been presented by the IPCC AR5 (Church et al., 2013) for a range of climate change scenarios. These projections include estimates of (1) global thermal expansion, (2) ice sheet mass changes from surface mass balance, (3) ice sheet mass changes from ice dynamics, (4) glacier mass changes and (5) changes in land water (from ground water extraction and reservoir impoundment). Time series for each component (1)-(5), under different RCPs, over the 21st century are available from the IPCC AR5 Chapter 13 supplementary data files (http://www.climatechange2013.org/ report/full-report/). These time series are derived from the direct output of climate models (1), combining climate model projections with empirical relationships and/or glacier models (2 and 4) and bounding scenarios based on the scientific literature (3 and 5). The upper and lower limits of each time series represent the "likely range" of GMSL change, taking the IPCC AR5 assessment that there is a $>=66 \%$ chance that the observed sea level rise would fall within these bounds for a given RCP. The additional uncertainty implied by this arises from the authors' expert judgement of methodological or structural uncertainty that is not captured by the CMIP5 ensemble.

Local changes in time-mean sea level associated with ocean mass changes (2-5 above) over the 21st century are evaluated using the fingerprint patterns of Slangen et al. (2014), which represent the ratio of a local sea level change to a unit rise in GMSL for each contributing term. Time series of each term obtained from the AR5 supplementary data files (available at: http://www.climatechange2013. org/report/full-report/) were converted into local values for Singapore by multiplying by a local scaling factor (Table 1) derived from the Slangen et al. (2014) fingerprints, using the closest $1 \times 1^{\circ}$ grid box. Maps showing the ratio of local relative sea level change per unit of GMSL rise due to Greenland and Antarctica surface mass balance terms and changes in glacial ice content and land water use are shown in Fig. 2. Rates of glacial isostatic adjustment (GIA) for Singapore were determined using the combined ice and rheological models ICE-5G(VM2) (Peltier, 2004; http://www.atmosp. physics.utoronto.ca/ peltier/data.php), provided by Slangen et al. (2014), again taking data from the closest $1 \times 1^{\circ}$ grid box (Fig. 2f). Given the long timescales associated with GIA, the rates of change are assumed to be constant and independent of climate change scenario.

Local changes in ocean density (steric change) and circulation are also important for projections of regional sea level (e.g. Pardaens et al., 2011). We follow the approach taken in IPCC AR5 (Church et al., 2013; Slangen et al., 2014) and combine changes in local dynamic sea level (which represents local departures from global mean sea level) with changes in global thermal expansion to estimate the combined effects of local density and ocean circulation (the
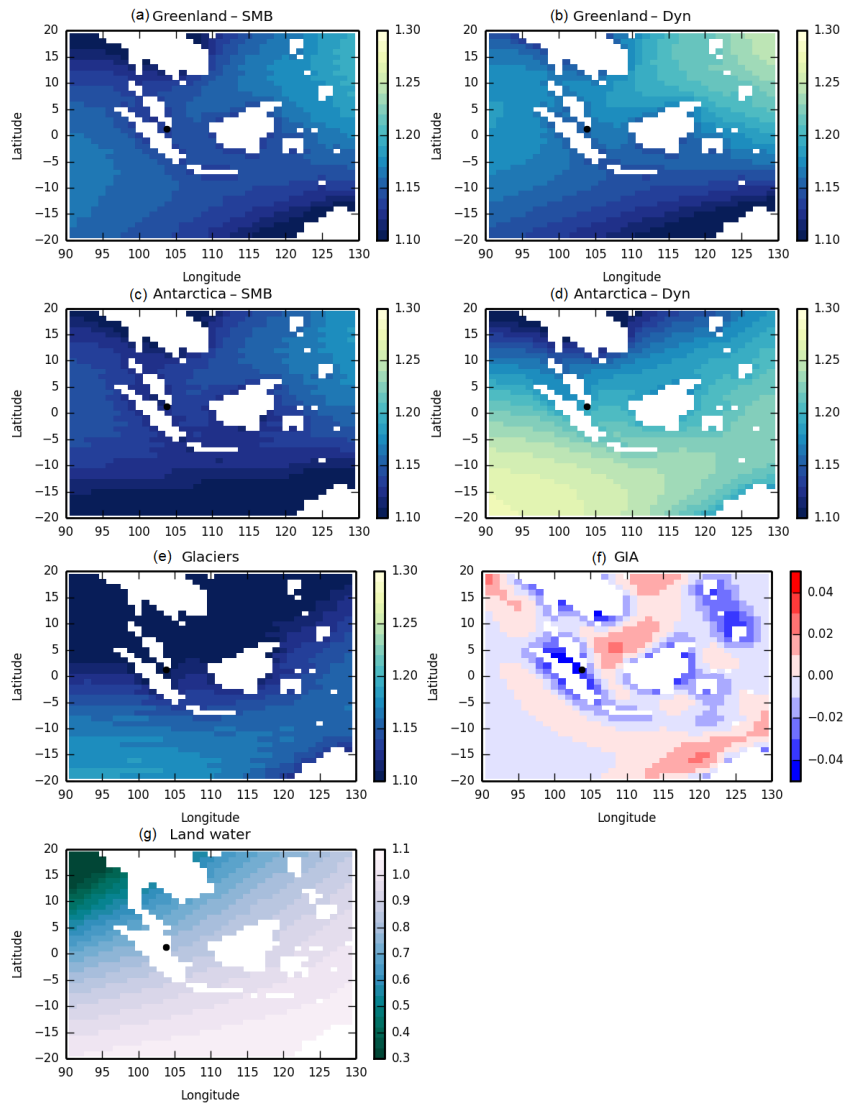

Figure 2. Spatial fingerprints for changes in (a) Greenland surface mass balance, (b) Greenland dynamical change, (c) Antarctica surface mass balance, (d) Antarctica dynamical change, (e) glaciers, (f) glacial isostatic adjustment and (g) changes in land water use. Panels (a)-(e) represent the ratio of local relative sea level change per unit of GMSL rise associated with mass input to the oceans. The location of Singapore is shown by the black circle. Source: Slangen et al. (2014).

"oceanographic" term). As has been shown by previous studies (Pardaens et al., 2011; Slangen et al., 2014), we find a large model spread in projections of regional oceanographic sea level rise (Fig. 3). However, all models show relatively weak gradients in the pattern of change in the vicinity of Singapore. This result appears to be largely independent of the underlying ocean model resolution, which varies across the CMIP5 models from about 2 to $0.3^{\circ}$.

The sensitivity of results to the choice of grid box was tested by selecting a primary and secondary grid box to represent Singapore. The difference in multi-model median estimates between boxes is about \pm 1 and $\pm 2 \mathrm{~mm}$ for RCP4.5 and RCP8.5, respectively. This represents less than $1 \%$ of the change signal and therefore is considered a negligible uncertainty. In order to provide an estimate of the projected oceanographic sea level rise that is continuous with time, it was assumed that the change signal (and model spread) emerges proportionally to the global thermal expansion time 
Table 1. Summary table of methodologies employed to estimate the different components of sea level rise at Singapore, including scaling factors used to convert global mean trends into local trends.

\begin{tabular}{|c|c|}
\hline Component & Methodology \\
\hline 1. Oceanographic sea level & $\begin{array}{l}\text { CMIP5 climate model estimates of global thermal expansion and dynamic sea leve } \\
\text { are combined for each model. Differences between the two periods 1986-2005 and } \\
2081-2100 \text { are computed for each climate change scenario. A multi-model mean } \\
\text { and spread in this component is extracted for Singapore using a nearest-neighbour } \\
\text { approach. Time series are constructed based on the assumption that the change sig- } \\
\text { nal emerges proportionally to AR5 estimates of global thermal expansion. }\end{array}$ \\
\hline 2. Glaciers & $\begin{array}{l}\text { Time series of global sea level rise from AR5 data files are scaled by a factor of } 1.11 \text {, } \\
\text { according to the spatial fingerprint information provided by Slangen et al. (2014). }\end{array}$ \\
\hline $\begin{array}{l}\text { 3. Greenland surface mass } \\
\text { balance }\end{array}$ & $\begin{array}{l}\text { Time series of global sea level rise from AR5 data files are scaled by a factor of } 1.14 \\
\text { according to the spatial fingerprint information provided by Slangen et al. (2014). }\end{array}$ \\
\hline $\begin{array}{l}\text { 4. Antarctica surface mass } \\
\text { balance }\end{array}$ & $\begin{array}{l}\text { Time series of global sea level rise from AR5 data files are scaled by a factor of } 1.13 \text {, } \\
\text { according to the spatial fingerprint information provided by Slangen et al. (2014). }\end{array}$ \\
\hline 5. Greenland dynamics & $\begin{array}{l}\text { Time series of global sea level rise from AR } 5 \text { data files are scaled by a factor of } 1.16 \text {, } \\
\text { according to the spatial fingerprint information provided by Slangen et al. (2014). }\end{array}$ \\
\hline 6. Antarctica dynamics & $\begin{array}{l}\text { Time series of global sea level rise from AR5 data files are scaled by a factor of } 1.19 \\
\text { according to the spatial fingerprint information provided by Slangen et al. (2014). }\end{array}$ \\
\hline 7. Land water storage & $\begin{array}{l}\text { Time series of global sea level rise from AR5 data files are scaled by a factor of } 0.81 \text {, } \\
\text { according to the spatial fingerprint information provided by Slangen et al. (2014). }\end{array}$ \\
\hline $\begin{array}{l}\text { 8. Glacial isostatic adjust- } \\
\text { ment (GIA) }\end{array}$ & Estimate based on ICE5G (Peltier, 2004) model as provided by Slangen et al. (2014) \\
\hline 9. Inverse barometer & $\begin{array}{l}\text { Assessed from AR5 supplementary data files. Not included in projections, given the } \\
\text { negligible contribution. }\end{array}$ \\
\hline
\end{tabular}

series of the IPCC AR5. This approach is justified since, to a good approximation, all models show a linear relationship between the local oceanographic sea level change near Singapore, and global thermal expansion (this relationship in demonstrated in Fig. A1 for all CMIP5 models for RCP4.5 and RCP8.5). This permits us to estimate the sea level change for the Singapore region throughout the 21 st century for each scenario.

IPCC AR5 estimates of the effect of changes in atmospheric loading for the RCP4.5 and RCP8.5 scenarios are available as part of the Chapter 13 supplementary data files (Church et al., 2013). However, the projections for the Singapore region are very small compared to the other terms representing only about $1 \%$ of the total estimated sea level change, with relatively little spread among different model projections. Given the substantial combined uncertainties of the leading terms in total sea level change, we do not include the inverse barometer effect in our final projections as we consider this term constitutes a negligible contribution to projected sea level change.

The sea level change for Singapore was computed as the difference between the 1986-2005 and 2081-2100 periods. The median of the model ensemble change was taken as the central estimate and the 5th and 95th percentiles were calcu- lated based on the multi-model standard deviation, assuming a normal distribution. Time series of each of the terms listed in Table 1 have a central estimate (based on the median for all terms except the oceanographic term, for which the mean is used) and both an upper and lower bound, which are indicative of the 5th and 95th percentiles of the distribution and/or the likely range assessed in the IPCC AR5. The central estimates of the different components are simply added together to arrive at values for total sea level change at Singapore. To combine the associated uncertainties we follow the approach outlined by Church et al. (2013), in which total uncertainty $\left(\sigma_{\text {tot }}\right)$ expressed as a variance is estimated according to Eq. (1),

$$
\begin{aligned}
\sigma_{\text {tot }}^{2} & =\left(\sigma_{\text {ocean }}+\sigma_{\text {smb_a }}+\sigma_{\text {smb_g }}\right)^{2}+\sigma_{\text {glac }}^{2}+\sigma_{\mathrm{LW}}^{2} \\
& +\sigma_{\text {dyn_a }}^{2}+\sigma_{\text {dyn_g }}^{2},
\end{aligned}
$$

where $\sigma_{\text {ocean }}, \sigma_{\text {smb_a }}, \sigma_{\text {smb_g }} \sigma_{\text {glac }}, \sigma_{\text {LW }}, \sigma_{\text {dyn_a }}$ and $\sigma_{\text {dyn } \_g}$ represent uncertainties in sea level rise projections due to changes in oceanographic processes, Antarctic surface mass balance, Greenland surface mass balance, glaciers, land water, Antarctic dynamics and Greenland dynamics, respectively. It is assumed that the first three terms, which have a strong correlation with global air temperature, have corre- 

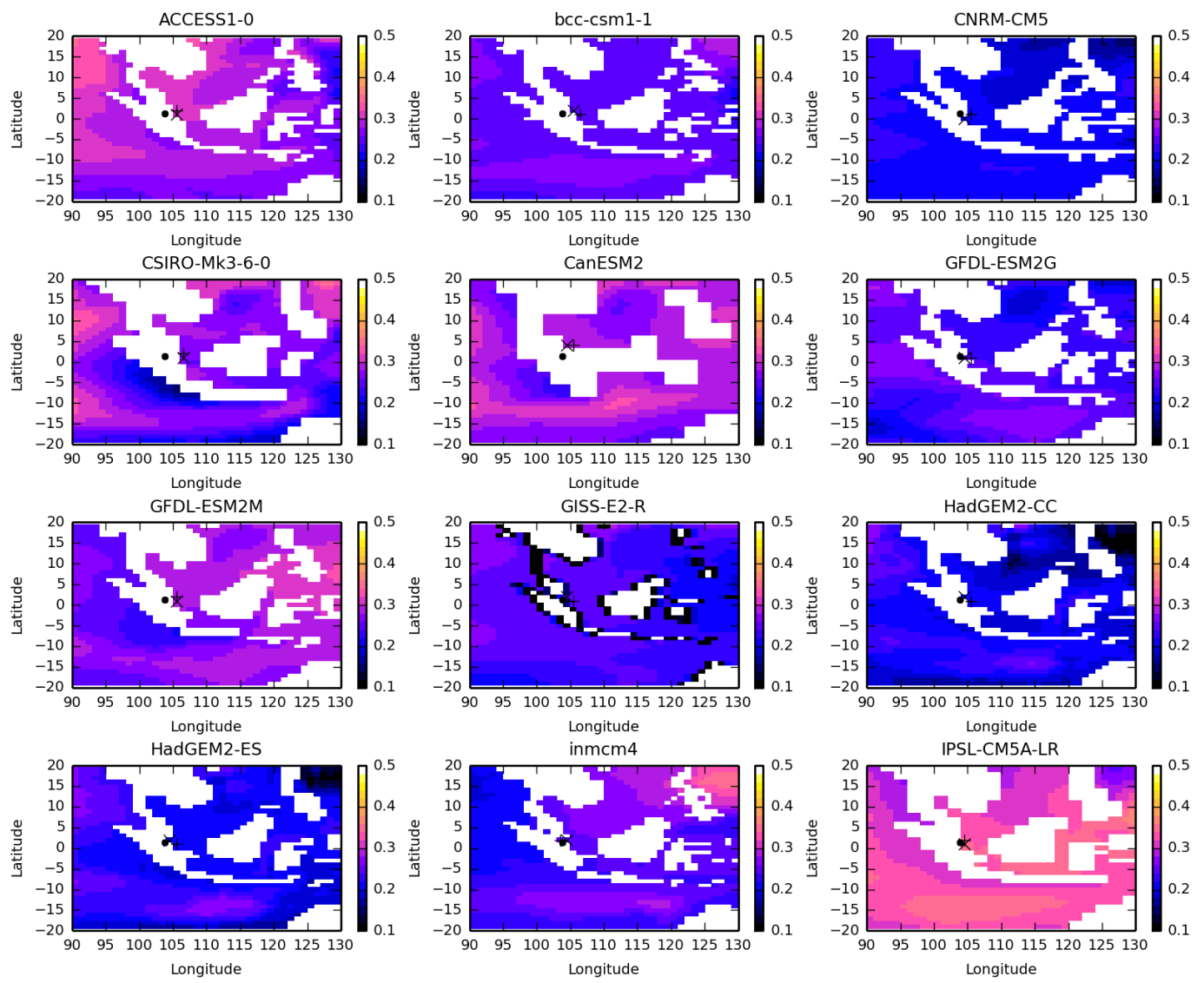

Longitude
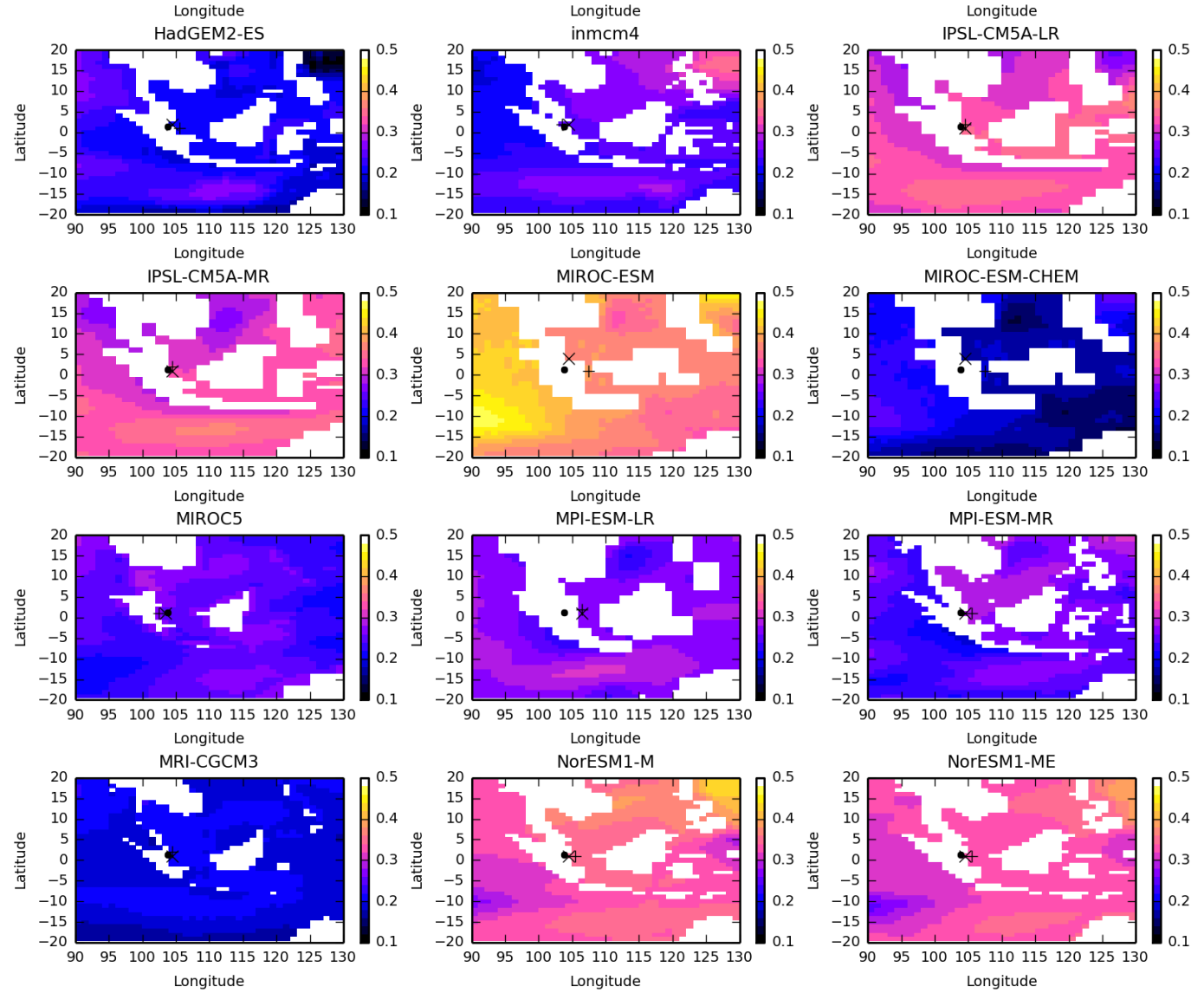

Figure 3. Projections of steric/dynamic sea level rise (metres) for 21 CMIP5 models under RCP8.5, computed as the difference between 1986-2005 and 2081-2100. The location of Singapore is shown by the black circle. The primary and secondary grid boxes used to extract time-mean sea level for Singapore are shown by an $\times$ and + , respectively. Note the grid box selections for GISS-E2-R are away from potential problem areas for the land mask. 
lated uncertainties and can therefore be added linearly. This combined uncertainty is then added to the other components' uncertainties in quadrature. The uncertainties in the projected ice sheet surface mass balance changes are reported to be dominated by the magnitude of climate change, rather than their methodological uncertainty (see AR5 Chapter 13 supplementary materials for details), while the uncertainty in the projected glacier change was assumed to be dominated by methodological uncertainty. We do not include an uncertainty contribution for GIA or the inverse barometer effect (which as noted above has a negligible contribution to sea level projections at Singapore) in our method.

\subsection{Design of model study}

The surge and wave projections described in this work were conducted utilising high-resolution $(12 \mathrm{~km})$ regional atmospheric simulations, forced at the open boundaries by a selection of nine Global Climate Model (GCM) solutions generated for the IPCC AR5 (IPCC AR4, 2007; see McSweeny et al., 2015 for further details on downscaled atmospheric simulations). Figure 1a shows the downscaled atmospheric model domain. Computational expense dictated the need to select only the most suitable GCMs from which to generate downscaled atmospheric solutions. Approaches for selecting climate models for downscaling are discussed in various papers (e.g. Wilby et al., 2009; Whetton et al., 2012). Criteria of particular importance in selecting climate models for impact studies include (a) that the climate models under historical conditions accurately represent the processes or features that are of particular relevance to the impact study and (b) that the climate models sample the range of projected change in the features of interest (Whetton et al., 2012). Both these criteria were considered when selecting models for downscaling. In particular, it was essential that the GCMs used should appropriately represent wind speed during both the Northern Hemisphere and Southern Hemisphere monsoon systems. Selection was further constrained by the availability of suitable data on the CMIP5 archive. Of nine downscaled atmospheric simulations conducted, four were selected to force the high-resolution surge and wave models: HadGEM2-ES, CNRM-CM5, IPSL-CM5A-MR and GFDLCM3. These four models sample a range of projected change in wind speed and include the model GFDL-CM3, which out of the nine downscaled atmospheric simulations exhibited the largest area-averaged change in $850 \mathrm{hPa}$ wind speeds during both the SW and NE monsoon seasons. Computational expense also dictated that downscaled ocean simulations could only be conducted for a single RCP. We therefore chose RCP8.5, which is expected to give the largest climate change signal.

Surge and wave climate projections were generated extending from 1970 to 2100 . An additional atmospheric solution downscaled from the ERA-Interim (Dee et al., 2011) global atmospheric reanalysis was used to force historical surge and wave simulations extending from 1980 to 2010 . These historical simulations were used to compare model results with contemporary observations.

\subsection{Description of surge model}

The model used to generate surge projections was the $\mathrm{Nu}-$ cleus for European Modelling of the Ocean (NEMO) version 3.4 ocean model (www.nemo-ocean.eu, Madec, 2008). NEMO was run with a horizontal resolution of $1 / 12^{\circ}$ and nine sigma levels in the vertical. The domain extended from 95 to $117^{\circ}$ east and from $10^{\circ}$ south to $17^{\circ}$ north as indicated in Fig. 1a. Initial conditions specified a constant uniform density and this was maintained throughout the simulations by setting surface heat and salt fluxes to zero. Hence, NEMO was effectively run as a barotropic model. Tidal forcing was applied at the open boundary as a time series of sea-surface elevation representing 15 harmonic tidal constituents: Q1, O1, P1, S1, K1, 2N2, MU2, N2, NU2, M2, L2, T2, S2, K2 and M4. In order to allow tides to propagate through the narrow and very shallow $(<12 \mathrm{~m}$ in places) Strait of Malacca, it was necessary to modify the $z$ envelope (which allows sigma levels to intercept land in regions of steep topography, thus preventing steep gradients in the vertical levels that may introduce pressure gradient errors) such that the minimum number of vertical levels at any location was 7 . The model was run with logarithmic bottom friction and a $4 \mathrm{~s}$ barotropic time step. Atmospheric forcing was prescribed as hourly mean sea level pressure and $10 \mathrm{~m}$ wind fields. For the case of the 4 GCM-forced simulations, atmospheric forcing was prescribed at the same horizontal resolution as the ocean model. ERA-Interim (Dee et al, 2011) atmospheric forcing was prescribed at $\sim 80 \mathrm{~km}$ resolution. Sea-surface height was recorded at hourly intervals.

The climate models used to generate the atmospheric forcing use different calendar years (only CNRM-CM5 uses a Gregorian calendar, GFDL-CM3 and IPSL-CM5A-MR use a 365-day calendar, and HadGEM2-ES uses a 360-day calendar. This introduced difficulties in maintaining consistency between tidal and atmospheric forcing. Consequently the surge model was not run as a transient simulation, rather each year was run independently, following a 5-day spin-up. To avoid splitting model simulations during the winter monsoon period when extreme events are most common, the model was run 360 days forward in time from 1st July. Atmospheric forcing for the 5-day spin-up was taken from the last 5 days of June during the start year of the simulation.

The surge metric with which we are concerned in this study is skew surge. Skew surge is the difference between the elevation of the predicted astronomical high tide and the maximum high water observed during the same tidal cycle (e.g. de Vries et al., 1995). Skew surge is considered a more significant and practical measure than surge residual (the difference between the predicted astronomical tide and the observed water level at any time during a tidal cycle). This is 
because winds are most effective at generating surge in shallow water, meaning peaks in surge residual are typically obtained prior to the predicted high water (Horsburgh and Wilson, 2007). In order to allow for calculation of skew surge, an additional NEMO simulation was conducted extending from 1970 to 2100 with tidal forcing only (i.e. without any meteorological forcing).

\subsection{Description of wave model}

Wave simulations were performed using WAVEWATCHIII (WW3) (Tolman, 1997, 1999, 2009), a third generation wave model developed by National Oceanographic and Atmospheric Administration/National Centers for Environmental Prediction (NOAA/NCEP). We used version 3.14 with Tolman and Chalikov (1996) physics. In a spectral wave model, the choice of source terms dictates how the model represents energy input through winds, and dissipation through wave breaking and white capping. Regional validation runs were initially performed using two sets of source terms for comparison: WAM cycle 4 (Monbaliu et al., 2000) and Tolman and Chalikov (1996). The latter has problems with shorter fetch, as wind waves grow slowly and dissipate slowly causing a model bias. WAM cycle 4 has a reduced bias overall but also reduced performance in the tropics. Very little difference was found between these two source terms for the domain of interest and consequently Tolman and Chalikov (1996) source terms were chosen due to the quicker integration time. The regional model was run at $1 / 12^{\circ}$ resolution on a grid extending from 95 to $117^{\circ} \mathrm{E}$ and $9^{\circ} \mathrm{S}$ to $14^{\circ} \mathrm{N}$ as indicated in Fig. 1a. The model was run with a global time step of $900 \mathrm{~s}$, a spectral resolution of 30 frequency bins, and 24 directional bins. The model was forced at the surface by hourly mean $10 \mathrm{~m}$ wind speed at $1 / 12^{\circ}$ resolution. Significant wave height, mean wave energy period, mean wave direction, mean directional spread and mean wave period were recorded at hourly intervals. We focus here on projected changes in significant wave height.

In order to capture swell incoming at the open boundaries of the regional domain, a $50 \mathrm{~km}$ resolution global wave model was also run, forced with 3 hourly wind and daily sea ice values taken from the CMIP5 models. The global WW3 domain consisted of a spherical multiple cell grid with a resolution of $0.7031250^{\circ} \times 0.4687500^{\circ}$, which extended from $\sim 80^{\circ} \mathrm{N}$ to $80^{\circ} \mathrm{S}$. Three-hourly wind data were not available for the entire future period for IPSL-CM5A-MR, and so daily data were used between 2046 and 2065. The model produced nest files, which were used to force the regional domain at $3 \mathrm{~h}$ intervals.

\subsection{Model validation}

To assess model performance in simulating local tides, harmonic analyses of modelled and observed sea-surface heights were performed using T_TIDE (Pawlowicz et al.,
2002). Comparisons were made at four tide gauge stations situated close to Singapore: Raffles Light House, Keling, Tanah Merah and Kukup (see Fig. 1b for locations). Simulated SSH time series were extracted from the closest model grid points to the tide gauge locations. Amplitudes and phases of each tidal constituent were then compared using scatter diagrams. During initial test runs the model was tuned by adjusting the bottom friction parameterisation in order to best represent tidal range, and in particular maximum spring high-water events in the immediate vicinity of Singapore.

To assess model performance in representing surge events, simulated annual maximum extreme water levels at grid point "a" (Fig. 1b) were compared to an 18-year (19962013) tide-gauge record from Raffles Light House. Six nonoverlapping samples of 18 consecutive years were extracted from each of the model simulations. Return levels were compared to average recurrence interval (ARI) measured in years. For large return periods ARI is very similar to return period (RP; defined as the reciprocal of the annual exceedance probability). ARI and RP are related by Eq. (2).

$\mathrm{ARI}=\frac{1}{\log \frac{\mathrm{RP}}{\mathrm{RP}-1}}$

The advantage of using ARI is that a Gumbel distribution fitted to the tide gauge observations appears as a straight line on a plot of return level versus ARI, even for small ARI. A Gumbel distribution was fitted to the tide gauge observations and to each of the samples of model data, to give a distribution of model-scale parameters. This distribution, along with the scale parameter of the observations, is used to assess whether the observations lie comfortably within the distribution of the model samples.

Modelled significant wave heights were compared to those derived from EnviSat satellite observations (Atlas et al., 2011), utilising the along-track level-2 data collected between 2003 and 2005. Data were obtained via the Globwave data portal (http://globwave.ifremer.fr/). All satellite data falling within the model domain during this period were directly compared to the closest model data point in both space and time. A suite of metrics was then generated from the model-data comparisons: mean errors (ME), root mean square errors (RMSE), correlation coefficients (PC) and standard deviations (SD).

\subsection{Analysis of extreme events}

Analysis of extreme skew surge and significant wave height return levels was limited by the length of the model simulation. Furthermore, there was considerable interannual variability in both modelled and observed extreme water levels, making long-term trends difficult to identify against the background natural variability. To address these limitations a statistical model was used, firstly to derive return levels for periods longer than the period of the simulation, secondly to better model the behaviour of the system at any given return 
period and thirdly to make a more informed assessment of the century-scale trends. The model used was the generalised extreme value (GEV) distribution (e.g. Coles, 2001; Hosking et al., 1985; Huerta and Bruno, 2007; Kotz and Nadarajah, 2000; Méndez et al., 2007, 2008) applied to annual maximum skew surge and significant wave height values. We tested the impact of using the $R$ largest events ( $R$ ranging from 1 to 5) each year, subject to a separation of at least $120 \mathrm{~h}$ in an effort to ensure independence. Results were not strongly sensitive to the value of $R$, and furthermore for the GFDL and IPSL simulations the parameter estimates did not remain stable as $R$ increased, which is a requirement for making meaningful use of $R>1$ (Coles, 2001). Thus, for consistency $R=1$ (annual maxima only) was selected for all simulations. Invoking the external types theorem (ETT) we assume that the data are well approximated by a GEV distribution since each data point is representative of the extreme of a large data block. On fitting a generalised extreme value distribution to the data, the three parameters of the GEV distribution (location, scale and shape) can be used to make statements about the probability of the annual maximum exceeding a particular level. The location parameter of the GEV is analogous to the mean of the normal distribution meaning that a change slides the whole distribution up or down. The scale parameter of the GEV is analogous to the standard deviation of the normal distribution, meaning that an increase widens the spread of the distribution, in the case of the GEV moving the long-period return levels further from the short-period return levels. Thus, a change in either parameter can affect the long-period return levels. In this work we considered the century-scale change in location and scale. It is assumed that the shape parameter remains constant for a given simulation. The GEV distribution was fitted to modelled extreme skew surge and wave heights time series over the 1970-2099 period. Allowing the location parameter to change accommodates potential change in all extreme events (e.g. at both long and short return periods). Allowing the scale parameter to change accommodates the potential for an increase (or decrease) in the spread of extreme events (e.g. an increase in intensity of the most extreme surges accompanied by a decrease in intensity of the more frequent surges). A comparison of the quality of the stationary and non-stationary fits gives an indication of the significance of any trend. Linear century-scale trends in return level associated with any given return period were diagnosed from the non-stationary GEV fit to the data. In order to produce a four-model mean $(\mu)$ trend estimate, the mean of the ensemble central estimates of trend was taken. The (Bessel-corrected) standard deviation of these four $(\sigma)$ then represents the uncertainty in the projection. We then identify $(\mu-1.64 \sigma)$ as the lower bound and $(\mu+1.64 \sigma)$ as the upper bound. Note that the implied symmetry is in the distribution of trends, not the distribution of the extremes themselves, which will in general be asymmetrical. We note that a limitation of the statistical modelling is an implicit assumption that the behaviour of the extremes
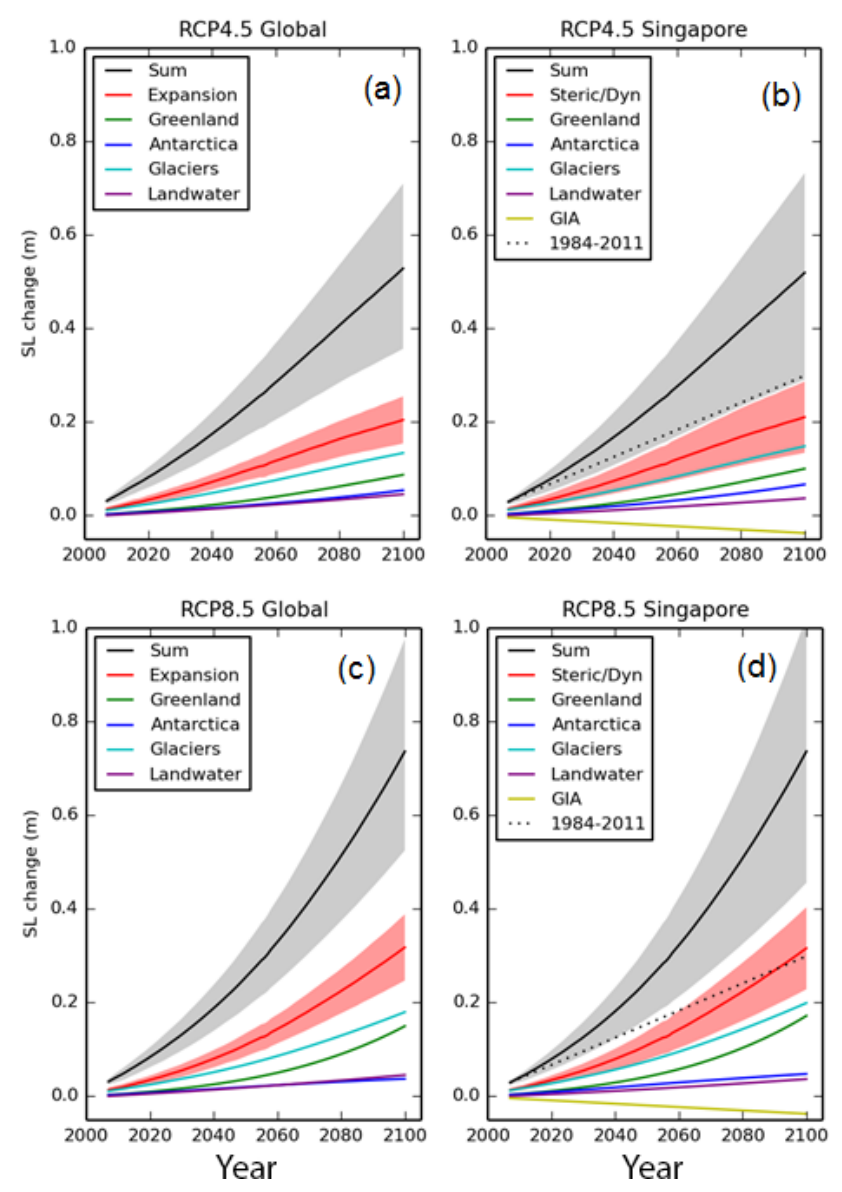

Figure 4. Projections of sea level rise relative to 1986-2005 and its contributions as a function of time for (a) global mean sea level (RCP4.5), (b) Singapore region (RCP4.5), (c) global mean sea level (RCP8.5) and (d) Singapore region (RCP8.5). Lines show the median projections. The likely ranges for the total and thermal expansion or steric/dynamic sea level changes are shown by the shaded regions. The contributions from ice sheets include the contributions from ice sheet rapid dynamical change. The dotted line shows an extrapolation of the observed 1984-2011 rate of sea level change for the Singapore Strait reported by Tkalich et al. (2013).

in 1 year is independent of the behaviour of the extremes in neighbouring years. In fact we expect some autocorrelation due to multi-annual cycles in the climate system. This can reduce the effective number of degrees of freedom compared to the number implied by the assumption of independence. In this circumstance there is a risk of diagnosing a trend as statistically significant simply because the assumed number of degrees of freedom is too large. However, we find a posteriori that this is not a big issue in this work since we do not diagnose large significant positive trends. 


\section{Model validation}

\subsection{Surge model}

Comparisons of modelled and observed tidal amplitudes and phases at four tide gauge stations (Raffles Light House, Kukup, Tanah Merah and Keling, located as indicated in Fig. 1b) are presented in Fig. 4a for the seven largest tidal constituents (M2, N2, K2, K1, O1, M4 and P1). Modelled tidal amplitudes compare well to those observed, particularly for the dominant semi-diurnal constituents (M2, N2 and K2) for which differences between observed and modelled amplitudes averaged $1.1 \mathrm{~cm}$. The smaller diurnal components (K1, O1, M4, P1) are less well captured by the model with a mean difference between observed and modelled amplitudes of $3 \mathrm{~cm}$. Tidal phase is also well captured by the model (Fig. 5b). Modelled and observed tidal phases differed by less than $50^{\circ}$, with the exception at two stations of the smallest amplitude (M4) constituent.

Model skill in simulating extreme events is demonstrated by comparing simulated annual maximum extreme water levels at grid point "a" with annual maximum events extracted from an 18-year (1996-2013) tide-gauge record at Raffles Light House. In order to make a like-for-like comparison, six non-overlapping samples of 18 consecutive years were extracted from each of the model simulations. This treatment of the 130-year-long simulations as essentially stationary is justifiable in view of the very small trends described in Sect. 4.2. Extreme still-water return levels from each time series are plotted as a function of return period in Fig. 5a. Simulated return levels are approximately $20 \mathrm{~cm}$ larger than those derived from observations for all return periods. Importantly, it is also evident that the scale parameter (the gradient in Fig. 5a) of the model data is comparable to that of the observations. This reveals that the model is doing a good job of simulating the interannual variability (or "spread") in extreme water levels. The Gumbel distribution, fitted to the observations, is shown by the straight line in Fig. 6a. The distribution of model-scale parameters derived from the Gumbel distribution fitted to each of the samples of model data and the observations, is shown in Fig. 5b. (NB detrending observed and model data had little effect on the results shown in this plot.) It can be seen that the scale parameter of the observations lies comfortably within the distribution of the model samples, indicating that the observed-scale parameter is well modelled and that interannual variability in extreme water levels changes little over the course of the simulations. Aside from the mean sea level uncertainty, it is the uncertainty in the scale parameter that primarily determines the uncertainty in long-period return levels (i.e. the uncertainty in the most extreme events) under the Gumbel distribution. The good agreement between the modelled and observed-scale parameter increases our confidence in applying the model to project century-scale changes in extreme water levels.
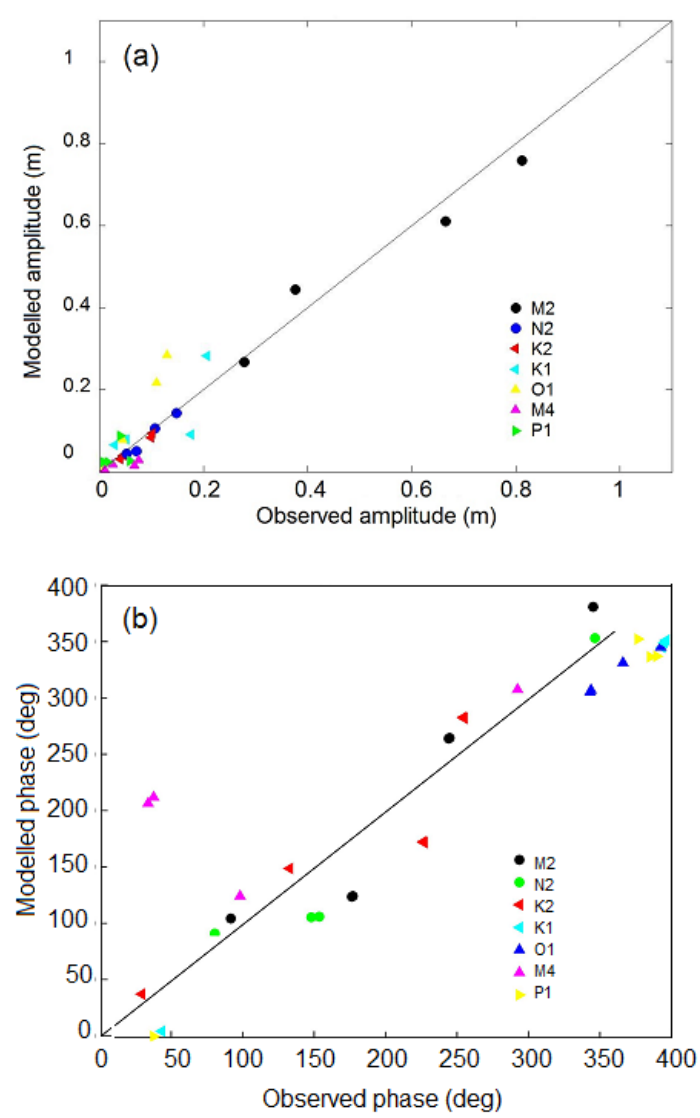

Figure 5. Comparison of modelled and observed (a) tidal amplitude and (b) tidal phase at four tide gauge stations close to Singapore (Keling, Tanah Merah, Raffles lighthouse and Kukup) station locations are marked in Fig. 1.

\subsection{Wave model}

The relationship between simulated significant wave heights and those observed by satellite altimetry across the model domain between 2003 and 2005 is summarised by a correlation coefficient of 0.85 , a standard deviation of $0.52 \mathrm{~m}$ and a mean bias of $-0.11 \mathrm{~m}$. These statistics demonstrate good model performance, comparable to the UK Met Office's operational wave model performance in tropical regions (Bidlot and Holt, 2006; Bidlot et al., 2000, 2007). Qualitative comparison of modelled and observed seasonal mean cycles in significant wave height at Singapore (not shown), demonstrates that the model is able to represent seasonality in significant wave heights at Singapore. A seasonal climatology generated from the ERA-Interim-forced simulation exhibits maximum significant wave heights of $\sim 0.3 \mathrm{~m}$ during the southwest monsoon season and maximum significant wave heights of $\sim 0.35 \mathrm{~m}$ during the northeast monsoon season. Significant wave heights decrease to $\sim 0.1 \mathrm{~m}$ outside of the monsoon seasons. 
Table 2. Median values and likely (in IPCC calibrated language - see Sect. 2.1) ranges (square brackets) for projections of time-mean sea level rise and its contribution in metres for 2081-2100 relative to 1986-2005 for Singapore and the global average (as reported in Table 13.5 of AR5, Church et al., 2013).

\begin{tabular}{lcc|cc}
\hline \multirow{2}{*}{$\begin{array}{l}\text { Sea level } \\
\text { component }\end{array}$} & \multicolumn{2}{c}{ RCP4.5 change $(\mathrm{m})$} & \multicolumn{2}{c}{ RCP8.5 change $(\mathrm{m})$} \\
\cline { 2 - 5 } \begin{tabular}{lcc|c} 
Expansion/ \\
Oceanographic
\end{tabular} & $\begin{array}{c}0.20 \\
{[0.12,0.27]}\end{array}$ & $\begin{array}{c}0.19 \\
{[0.14,0.23]}\end{array}$ & $\begin{array}{c}0.27 \\
{[0.18,0.36]}\end{array}$ & $\begin{array}{c}0.27 \\
{[0.21,0.33]}\end{array}$ \\
\hline Glaciers & 0.14 & 0.12 & 0.18 & 0.16 \\
& {$[0.07,0.22]$} & {$[0.06,0.19]$} & {$[0.10,0.26]$} & {$[0.09,0.23]$} \\
\hline Greenland Surface & 0.05 & 0.04 & 0.08 & 0.07 \\
Mass Balance & {$[0.01,0.18]$} & {$[0.01,0.09]$} & {$[0.03,0.18]$} & {$[0.03,0.16]$} \\
\hline Antarctica Surface & -0.02 & -0.02 & -0.05 & -0.04 \\
Mass Balance & {$[-0.06,-0.01]$} & {$[-0.05,-0.01]$} & {$[-0.08,-0.01]$} & {$[-0.07,-0.01]$} \\
\hline Greenland & 0.05 & 0.04 & 0.06 & 0.05 \\
Dynamics & {$[0.01,0.07]$} & {$[0.01,0.06]$} & {$[0.02,0.08]$} & {$[0.02,0.07]$} \\
\hline Antarctica & 0.08 & 0.07 & 0.08 & 0.07 \\
Dynamics & {$[-0.01,0.19]$} & {$[-0.01,0.16]$} & {$[-0.01,0.19]$} & {$[-0.01,0.16]$} \\
\hline Land Water & 0.03 & 0.04 & 0.03 & 0.04 \\
\hline GIA & {$[-0.01,0.07]$} & {$[-0.01,0.09]$} & {$[-0.01,0.07]$} & {$[-0.01,0.09]$} \\
\hline
\end{tabular}

Table 3. Estimates of global sea level rise from the IPCC AR5 (Church et al., 2013) alongside our regional estimates for Singapore. Following the definitions in AR5, there is a 66-100\% chance that future sea level rise will fall within the ranges quoted. Based on current understanding, only the collapse of marine-based sectors of the Antarctic ice sheet, if initiated, could cause global mean sea level to rise substantially above the likely range during the 21 st century. This potential additional contribution cannot be precisely quantified but there is medium confidence that it would not exceed several tenths of a metre of sea level rise during the 21st century (Church et al, 2013).

\begin{tabular}{llrrr|rrr}
\hline & & \multicolumn{3}{c|}{2050} & \multicolumn{3}{c}{2100} \\
\cline { 3 - 8 } Scenario & & Central & Lower & Upper & Central & Lower & Upper \\
\hline \multirow{2}{*}{ RCP4.5 } & Global & 0.23 & 0.17 & 0.29 & 0.53 & 0.36 & 0.71 \\
& Singapore & 0.22 & 0.14 & 0.29 & 0.52 & 0.29 & 0.73 \\
\hline \multirow{2}{*}{ RCP8.5 } & Global & 0.25 & 0.19 & 0.32 & 0.74 & 0.52 & 0.98 \\
& Singapore & 0.25 & 0.17 & 0.32 & 0.74 & 0.45 & 1.02 \\
\hline
\end{tabular}

\section{Projections of regional sea level change}

\subsection{Time-mean sea level}

Time series of projected total sea level rise at Singapore and its components for RCP4.5 and RCP8.5 are presented in Fig. 6 . The changes between 1986-2005 and 2081-2100 for each contributing component are presented in Table 2. Central, lower and upper ranges of total sea level rise at Singapore out to 2050 and 2100 are presented in Table 3, alongside global mean values for comparison. The central estimates of total sea level rise at Singapore are similar to the global mean projections reported in the IPCC AR5. Glacier and ice sheet surface mass balance terms result in a larger increase in sea level at Singapore compared to the global mean. This is because there is a far-field rise in sea level as a result of the associated change in Earth's gravity field as the mass is redistributed away from high latitudes (Tamisiea and Mitrovica, 2011). The larger ice mass balance term is, however, offset by a negative contribution to sea level rise at Singapore from glacial isostatic adjustment. This is the result of additional ocean mass from the last deglaciation depressing the sea floor and causing mantle material to flow underneath the continents causing uplift (Tamisiea et al., 2014).

The uncertainty in projections of sea level rise at Singapore is substantially larger than for global mean projections, mainly due to the additional uncertainty associated with representation of regional oceanographic processes (the oceano- 

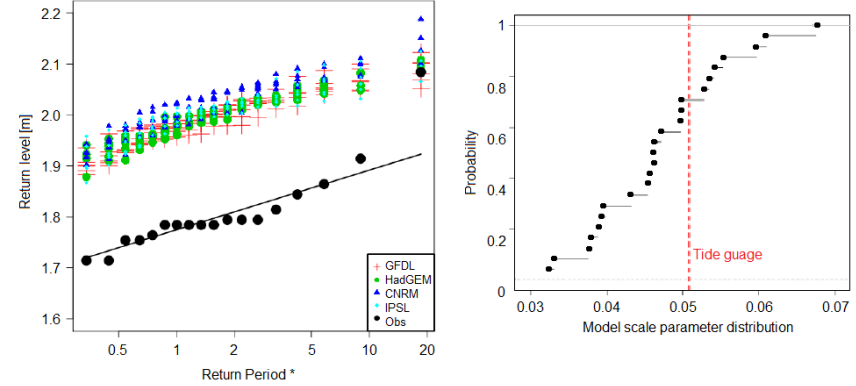

Figure 6. (a) Empirical return level data of extreme water level based on 18 years of tide gauge data from Raffles Light House (1996-2013), and 18-year long samples from the model simulations at grid point "a". The fitted Gumbel distribution of the observations is shown by the straight line. (b) Empirical cumulative density function of the scale parameters of the model samples, showing that the scale parameter of the tide gauge data sits well within the model distribution.

Table 4. Projected century-scale trends in skew surge for five return periods (excluding mean sea level change). Units are mm per century.

\begin{tabular}{lrrrrr}
\hline Period/years & 2 & 20 & 100 & 1000 & 10000 \\
\hline Lower & -20 & -40 & -63 & -90 & -120 \\
Central & 0 & -10 & -20 & -20 & -30 \\
Upper & 20 & 20 & 30 & 50 & 60 \\
\hline
\end{tabular}

graphic contribution to sea level change) by the coarseresolution CMIP5 models. Scaling up of the ice sheet and glacier terms using the Slangen et al. (2014) fingerprints also contributed to the increased uncertainty of the regional projections. This increased uncertainty is larger for RCP8.5 than for RCP4.5. Over the first half of the 21 st century the projected rate of sea level rise is similar for both RCP4.5 and RCP8.5. Hence, on this timescale, sea level rise projections are largely independent of emissions pathway, meaning the uncertainty range is dominated by methodological and model uncertainty. In both RCP4.5 and RCP8.5 there is a substantial acceleration in the rate of sea level rise over the 21 st century, particularly during the early and mid-periods of the 21 st century. A simple linear extrapolation of observed long-term regional trends (as reported for Singapore by Tkalich et al., 2013) is therefore likely to grossly underestimate future sea level rise.

\subsection{Surge changes}

Time series of annual maximum skew surge at grid point "a" from each of the four model simulations are presented in Fig. 7. (NB projected changes in surge and significant wave height both have very large spatial scales compared with the scale of Singapore. As a result, it was found that choice of model grid point did not significantly impact the
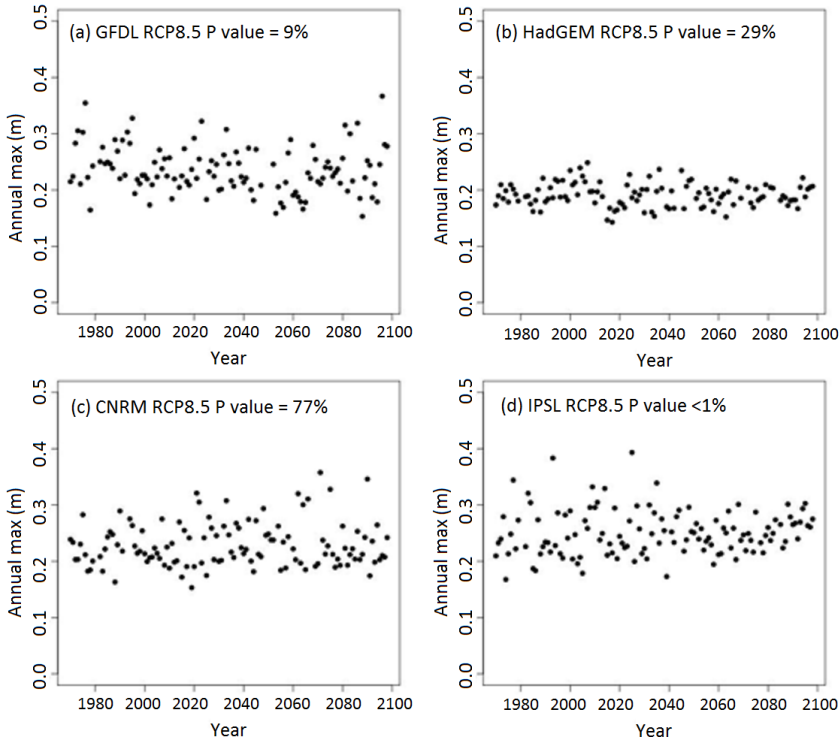

Figure 7. Annual maxima skew surge obtained from the (a) GFDL, (b) HadGEM, (c) CNRM and (d) IPSL-forced simulations. The $P$ value indicates the statistical significance of the improvement in fit when using a non-stationary GEV model: a large $P$ value indicates little improvement; a small $P$ value indicates significant improvement.

results.) For consistency all skew surge and significant wave height results presented in this paper are taken from grid point "a" (see Fig. 1 for location). For each simulation a non-stationary GEV model fit to the annual maximum significant wave height time series was used to diagnose a linear century-scale trend in return level associated with any given return period. For each simulation the $P$ value associated with the improvement in fit on moving from a stationary to a non-stationary GEV model is quoted in Fig. 7. There is always some model improvement with a non-stationary fit because more parameters are added to the statistical model (i.e. a linear time variation in both location and scale). Taking the CNRM model as an example, the $P$ value is $77 \%$, meaning the small amount of apparent non-stationarity in the CNRM data could easily arise by chance from random variations in stationary data. Thus, we cannot discount our null hypothesis of stationarity in the CNRM data. The IPSL model, on the other hand, is consistent with a visual assessment of the data. The $P$ value is very small and we conclude that this data are unlikely to arise from a truly stationary process. Visually, there is a strong suggestion in the IPSL data of a reduction in interannual variability over the 21 st century. The standard diagnostic of the quality of the fit of the stationary GEV distribution to the annual mean skew surge data for each simulation is included in Appendix A2 for each of the simulations. Projected century-scale trends in return level are reported in Table 4 and shown diagrammatically in Fig. 8. Treating the four models as a small ensemble of equally plausible sim- 
Table 5. Projected century-scale trends in significant wave height for five return periods due to storminess changes ( $\mathrm{mm}$ per century, to two decimal places).

\begin{tabular}{lrrrrr}
\hline Period/years & 2 & 20 & 100 & 1000 & 10000 \\
\hline Lower & -15 & -460 & -730 & -1260 & -2030 \\
Central & -30 & -140 & -220 & -390 & -620 \\
Upper & 80 & 190 & 290 & 490 & 780 \\
\hline
\end{tabular}

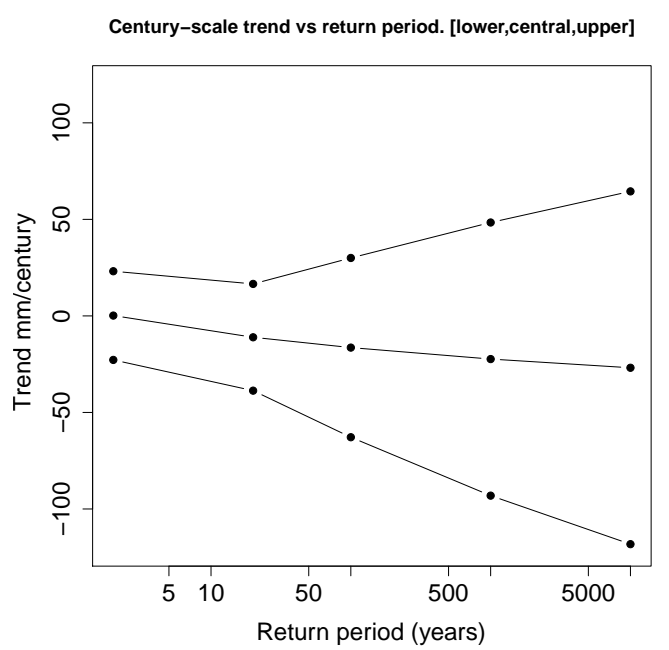

Figure 8. Projected century-scale trends in skew surge for five return periods due to storminess changes only (i.e. excluding mean sea level change; millimetres per century). Central, lower and upper estimates are shown.

ulations, we obtain an ensemble $[5,95 \%$ o of the diagnosed trend in the 100-year return level of $[-63,30] \mathrm{mm}$ century ${ }^{-1}$. We do not find a statistically significant trend in skew surge for any of the return levels tested. Uncertainties in skew surge trends are small compared to the uncertainties in projected mean sea level change of, e.g., $[450,1020] \mathrm{mm}$ (see Table 3) over the 21 st century under RCP8.5. As no statistically significant trends in skew surge return levels are projected for RCP8.5, we would not expect to find tends for the less severe RCP4.5 scenario.

\subsection{Wave changes}

Time series of annual maximum significant wave height at grid point "a" from each of the four simulations are presented in Fig. 9. The standard diagnostic of the quality of the fit of the stationary GEV distribution to the significant wave height and annual maxima for each simulation is shown in Appendix A3. All of the resulting projections of centuryscale trends were small and negative, with the exception of the IPSL-forced simulation for which a $35 \mathrm{~mm}^{\text {century }}{ }^{-1}$ increase in the 2-year return level was obtained. The model ensemble of the diagnosed trend in 100-year significant wave height return level is $[-0.73,0.29] \mathrm{mm}^{\text {century }}{ }^{-1}$. Diag-
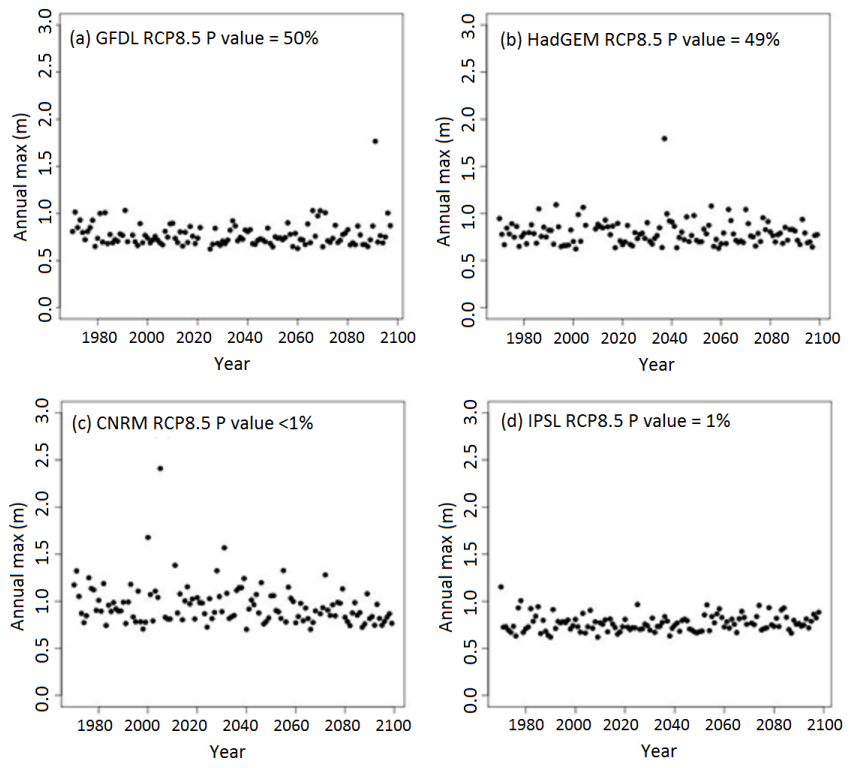

Figure 9. Simulated annual maxima of significant wave height (metres) obtained from the (a) GFDL, (b) HadGEM, (c) CNRM and (d) IPSL-forced simulations. The $P$ value indicates the statistical significance of the improvement in fit when using a non-stationary GEV model: a large $P$ value indicates little improvement; a small $P$ value indicates significant improvement.

nosed trends in 2, 20,100, 1000 and 10000-year return levels are given in Table 5 and presented diagrammatically in Fig. 10. The small sample size of four climate models and the large spread in projections of century-scale change in significant wave height at long return periods means that we cannot rule out positive trends, even though the central estimates of the trends are small and negative in each of the four models.

\section{Discussion}

The overriding conclusion from this study is that change in time-mean sea level will be the dominant process influencing the changing vulnerability of Singapore to coastal inundation over the 21 st century. Several studies have drawn similar conclusions for other parts of the world, e.g., in the North Sea (Sterl et al., 2009), around the UK (Lowe et al., 2009) and globally (Bindoff et al., 2007). It is notable that the central estimates of sea level rise by 2100 (of 0.52 and $0.74 \mathrm{~m}$ under the RCP4.5 and RCP8.5 scenarios, respectively) are of similar magnitude to the most damaging surge events recorded at Singapore over recent decades (in describing extreme events occurring since the 1970s, Tkalich et al. (2009) reported sea level anomalies ranging from 43 to $\sim 60 \mathrm{~cm}$ ). Hence, Singapore is a country particularly vulnerable to sea level rise. Wong (1992) previously highlighted this vulnerability, noting that by adding $1 \mathrm{~m}$ to current chart datum levels at Singapore (comparable to our upper estimate of a $1.02 \mathrm{~m}$ sea level 


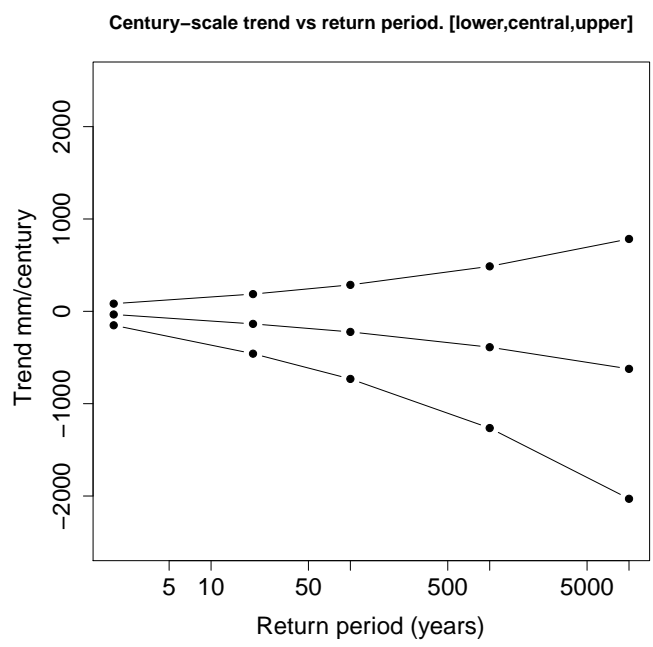

Figure 10. Projected century-scale trends in significant wave height for five return periods due to storminess changes only (i.e. excluding mean sea level change; mm per century). Central, lower and upper estimates are shown.

rise by 2100), the mean spring high water level of $3.8 \mathrm{~m}$ will be close to the highest recorded water level to date, of $3.9 \mathrm{~m}$.

The climate simulations presented in this work suggest there will be no significant change in the frequency of extreme storm surge or wave events during the 21st century over and above that due to mean sea level rise. Extreme events of the magnitude seen over recent decades will, however, have a much greater impact when superimposed on rising sea levels. Those involved in mitigating the potential impacts of future climate change on Singapore's coastline therefore need to combine projections of sea level rise with skew surge return level data. Site-specific projections of future extreme still-water level can be obtained by linearly combining return levels derived from tide gauge data with the sea level change projections presented in Table 3. (Tide-gauge data represent the best information available about presentday location-specific return levels; however, it is worth noting that uncertainties in the present-day return levels derived from relatively short tide-gauge records are likely to be a large component of the combined uncertainty in projected future return-level curves.) In the longer term there is potential to develop better estimates of current risk by combining model-derived information with observed time series. The skew surge joint probability method (Batstone et al., 2013) provides an approach to addressing this problem.

There are several caveats to the sea level, surge and wave projections presented in this study and we consider each in turn in the following paragraphs. Mean sea level projections are presented as likely (66-100\% probability) ranges for the RCP4.5 and RCP8.5 climate change scenarios, taking into account a number of uncertainties that cannot be robustly quantified with the present state of scientific knowledge. We note that recent studies have attempted to provide informa- tion outside of the IPCC likely range (Kopp et al., 2014; Jevrejeva et al., 2014) and this is an important topic of ongoing discussion by the research community (Hinkel et al., 2015). As noted previously, our sea level projections do not account for the unlikely event of a collapse of the marinebased sectors of the Antarctic ice sheet. Based on current understanding, AR5 assessed that such a collapse, if initiated, could cause global mean sea level to rise substantially above the given likely range during the 21 st century. This potential additional contribution cannot be precisely quantified, but the AR5 report assessed with medium confidence that it would not exceed several tenths of a metre of sea level rise during the 21st century (Church et al., 2013). This remains one of the most important structural uncertainties in projecting sea level extremes. An additional source of uncertainty arises from taking patterns of change associated with land ice, land water and GIA from a single source (i.e. the maps generated by Slangen et al., 2014). While Slangen's data are considered very credible estimates based on current understanding, we do not include here any estimate of uncertainties in sea level change that could arise from using alternative estimates of these patterns. The CMIP5 models, due to their low resolution, have limited ability to represent meso-scale hydrographic processes important to regional dynamics. Previous studies (e.g. Lowe et al., 2009; Perrette et al., 2013) suggest, however, that large-scale oceanic signals propagate freely into the coastal region, and are not overtly affected by the coarse resolution of the models. In common with previous studies (e.g. Lowe et al., 2009; Perrette et al., 2013), we assume that large-scale oceanic signals propagate freely into the coastal region. The effects of anthropogenic disturbance such as resource extraction and land reclamation on sea level projections are also not considered in this work. Finally, it is important to note that the probability attributed to the sea level projections is calculated without accounting for the potential effects of future seismic activity; the only vertical land movement process considered in this study being glacial-isostatic adjustment. It is possible that vertical land movement associated with seismic activity may dominate changes in relative sea level over decadal timescales. The Earth Observatory of Singapore state that

"Sea level could rise faster than the IPCC predicted after a big earthquake on the Sunda Megathrust. This is due to the overall tectonics of the region. After a big earthquake on the megathrust, the whole Sunda shelf will experience a subsidence." (http://www.earthobservatory.sg/ faq-on-earth-sciences/singapore-threatened-earthquakes-0)

There are a number of further caveats associated with the modelling of extreme events. Waves and surge have been modelled separately, meaning wave-surge interactions are not accounted for. Surge propagation from outside the boundaries of the surge model domain is also not considered (except by application of a static inverse barometer effect at the boundaries). Over shallow seas, however, wind is the dominant factor in surge generation, suggesting that 
surge propagation from outside the boundaries will not be a dominant factor in driving extreme water levels on the Sunda shelf (Horsburgh and Wilson, 2007). The impacts of changes in mean water depth on tidal resonance and on surge propagation are also not considered in this work. Pickering (2014) investigated the impact on tidal dynamics of raising GMSL by $2 \mathrm{~m}$ and found a change in mean high water level of the order of $10 \mathrm{~cm}$ around Singapore. Howard et al. (2010), Sterl et al. (2009) and Lowe et al. (2001) found in studies of the northwest European shelf that changing the water depth affects the time of arrival of a storm surge, but not the surge height. Hence, we suggest that any impact of rising sea levels on tidal dynamics will be small compared to sea level rise. Finally, our simulations assume a fixed coastline with no inundation. Further work with a high-resolution inundation model is required to understand the land area at risk from inundation due to sea level rise, and to design appropriate coastal defences to best mitigate this risk.

\section{Conclusions}

Regional projections of changes in long-term mean sea level and in the frequency of extreme storm surge and wave events over the 21st century have been generated for Singapore. Local changes in time-mean sea level were evaluated using the process-based climate model data and methods presented in the IPCC AR5. Regional surge and wave forecast simulations extending from 1970 to 2100 were generated using highresolution $(\sim 12 \mathrm{~km})$ regional surge (Nucleus for European Modelling of the Ocean - NEMO) and wave (WaveWatchIII) models. Ocean simulations were forced by four regional atmospheric model solutions, which were in turn nested within global atmospheric simulations generated for the IPCC AR4. The four climate models were chosen to best represent historical conditions and included the GFDL-CM3 model which exhibited the largest area-averaged changes in $850 \mathrm{hPa}$ wind speeds during both the southwest and northeast monsoon seasons. An additional atmospheric regional model simulation driven by a global atmospheric reanalysis was used to force historical regional ocean model simulations extending from 1980 to 2010. The hindcast simulation was used to demonstrate the skill of the models in simulating regional tides and surge events (through comparison to tide gauge data) and significant wave heights (through comparison to satellite altimetry data).

Central estimates of long-term mean sea level rise at Singapore by 2100 are projected to be $0.52 \mathrm{~m}(0.74 \mathrm{~m})$ under the RCP 4.5(8.5) scenarios, respectively. These values are very close to the global mean estimates presented in the IPCC AR5. Sea level rise at Singapore resulting from mass loss from ice sheets and glaciers is projected to be 10-15\% larger than the global mean. This will, however, be offset by elevation of the land mass due to glacial isostatic adjustment. The likely ranges of projected sea level rise at Singapore are substantially larger than the global mean projections, mainly due to the uncertainty associated with representation of regional oceanographic processes by the coarse-resolution CMIP5 models. Due to an acceleration in the rate of sea level rise throughout the early and mid-21st century, extrapolation of long-term tide-gauge records does not provide reliable estimates of future sea level change and systematically underestimates the magnitude of future sea level rise for both scenarios.

The $[5,95 \%$ o of diagnosed trend in 100-year skew surge return level, obtained by treating the four models as a small ensemble of equally plausible simulations is $[-63$, $30] \mathrm{mm}$ century $^{-1}$. The corresponding $[5,95 \%$ o of the diagnosed trend in 100-year significant wave height return level is $[-0.73,0.29]$ mm century $^{-1}$. The uncertainties in projected century-scale trend in skew surge and significant wave height are small compared to the uncertainties in projected mean sea level change of, e.g., $[450,1020] \mathrm{mm}$ over the 21 st century under RCP8.5. We find no statistically significant changes in extreme skew surge events and no statistically significant changes in extreme significant wave height under the RCP8.5 scenario over and above that due to mean sea level change using the four model ensembles. Our primary finding is then that change in time-mean sea level will be the dominant process influencing the changing vulnerability of Singapore to coastal inundation over the 21 st century. We note that the largest recorded surge residual in the Singapore Strait of $\sim 84 \mathrm{~cm}$ (Tkalich et al., 2009) lies between the central and upper estimates of sea level rise by 2100 .

\section{Data availability}

This study was conducted as part of Singapore's Second National Climate Change Study - Phase 1 (see http://ccrs.weather.gov.sg/publications-second-nationalclimate, McSweeney et al., 2015). Data are available through application to CCRS. 


\section{Appendix A}
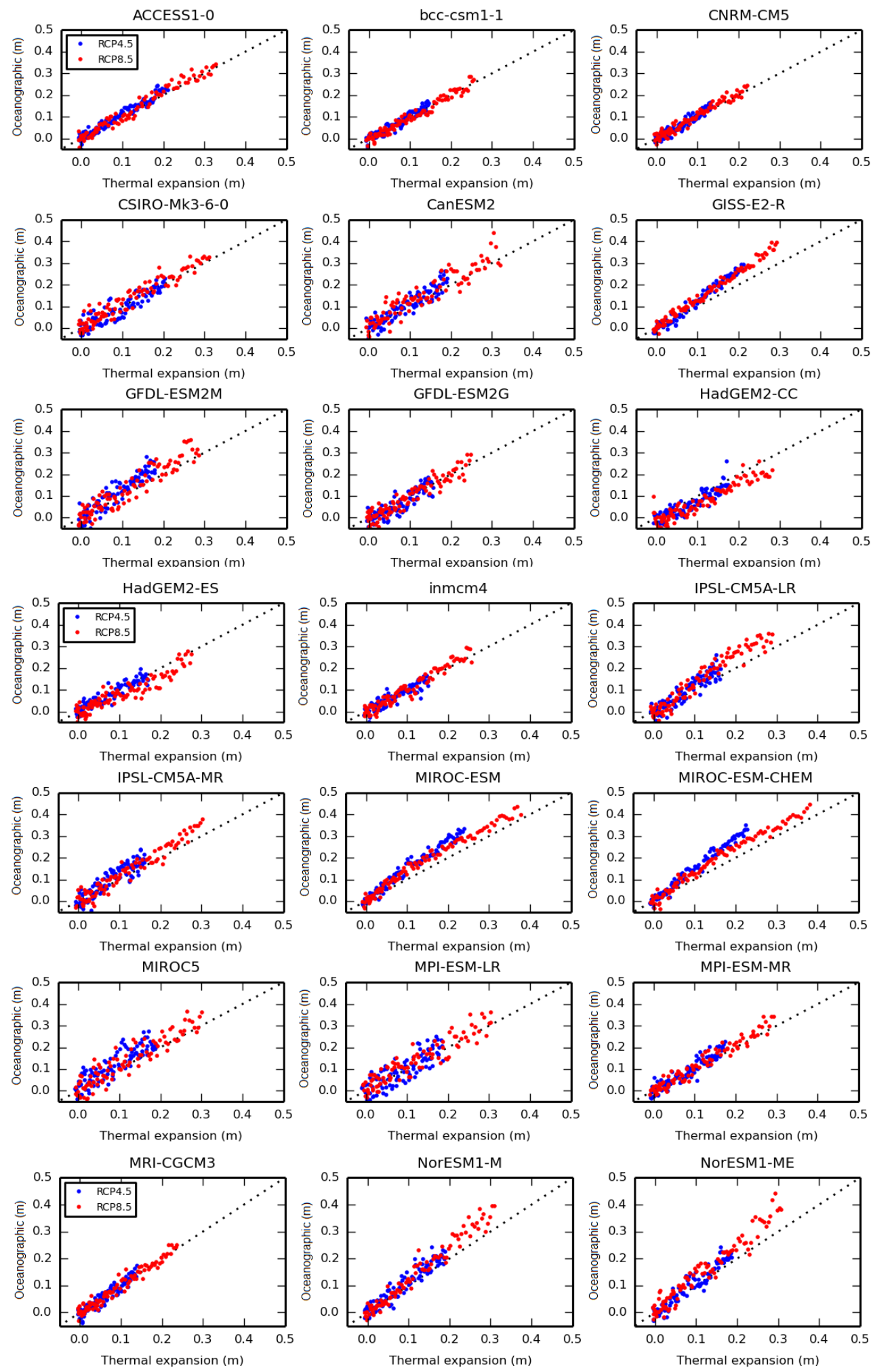

Figure A1. Regression between local oceanographic sea level change (due to steric plus dynamic processes) and global thermal expansion terms for each CMIP5 model under RCP4.5 and RCP8.5. 
(a) HadGEM
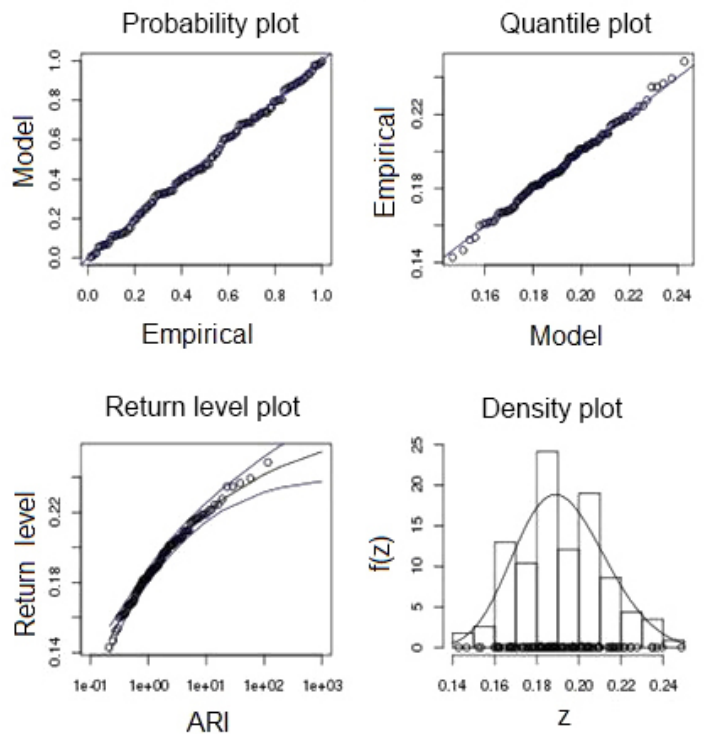

(c) CNRM
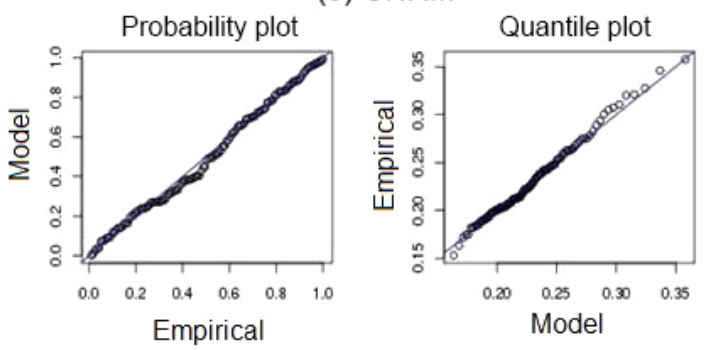

Return level plot
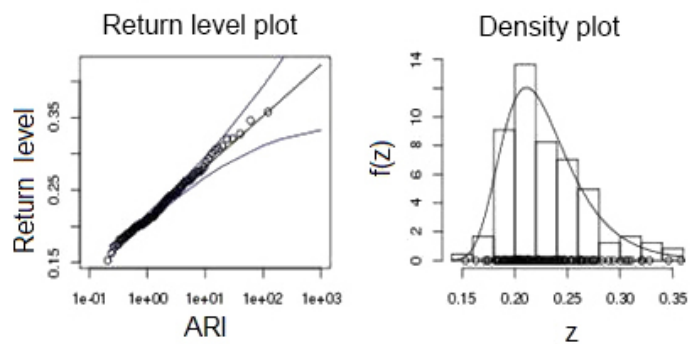

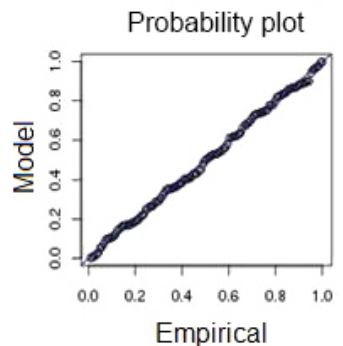

(b) IPSL
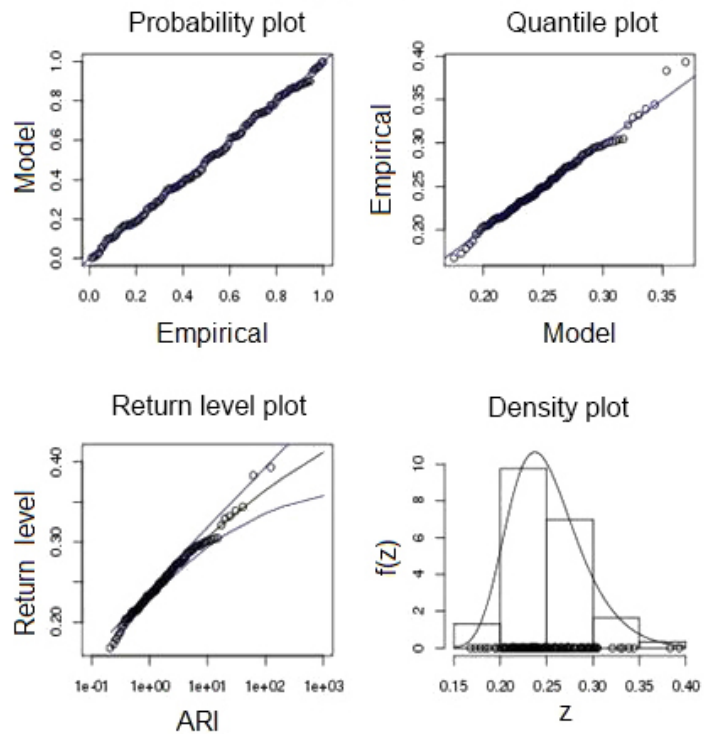

(d) GFDL
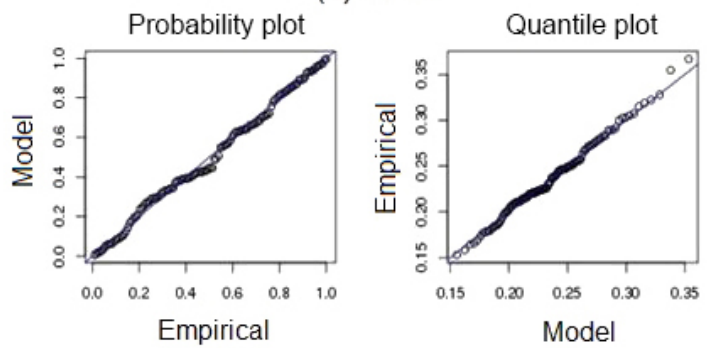

Return level plot

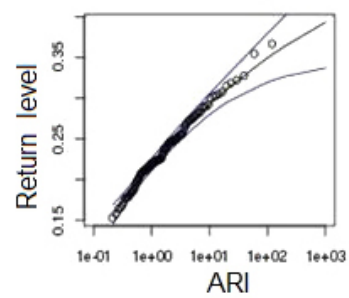

Density plot

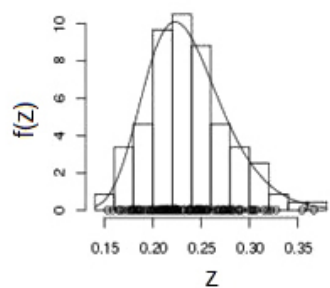

Figure A2. Standard diagnostic plots for stationary fit to skew surge annual maxima from (a) HadGEM2-ES, (b) IPSL, (c) CNRM, and (d) GFDL simulations. The quantile and probability plots compare the theoretical distribution fitted to the data with the actual data and give an indication of confidence in the fit of the return period. 
(a) HadGEM
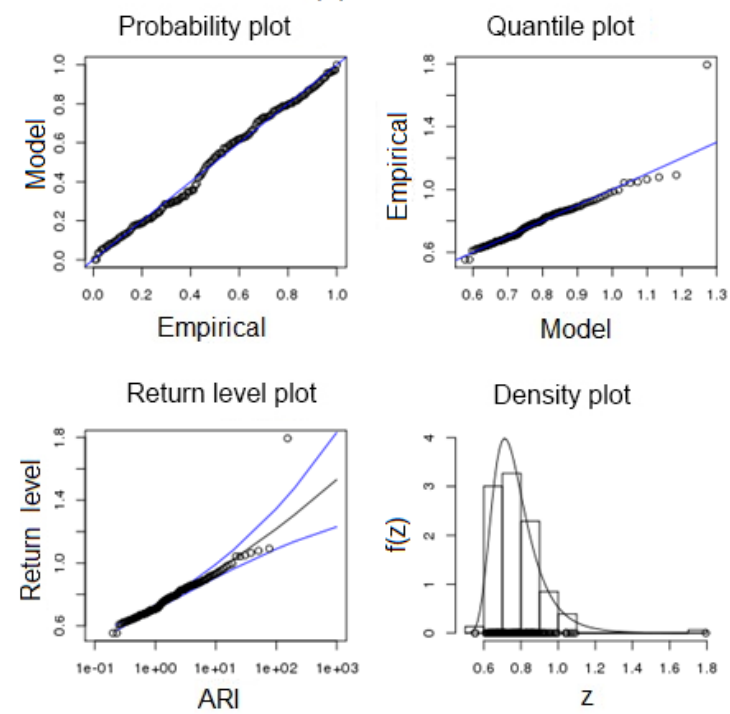

(c) CNRM
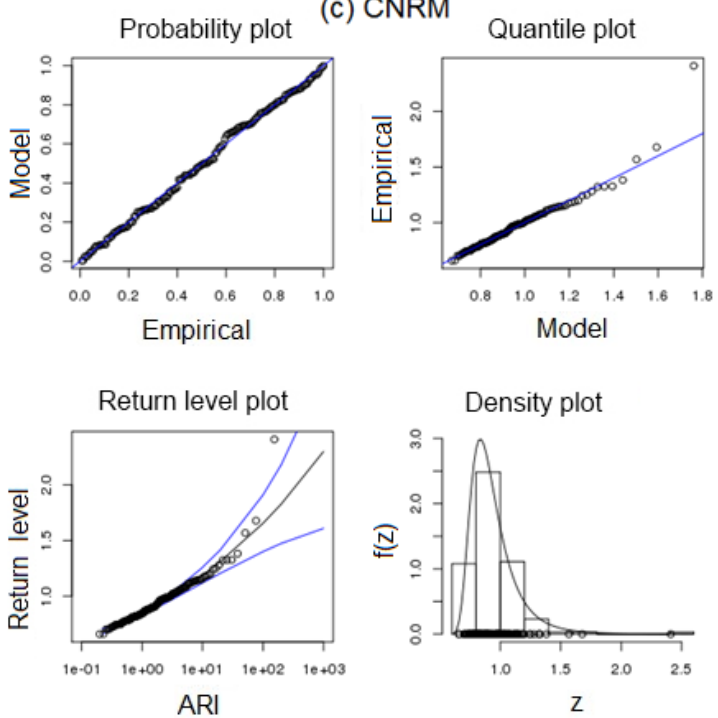

(b) IPSL
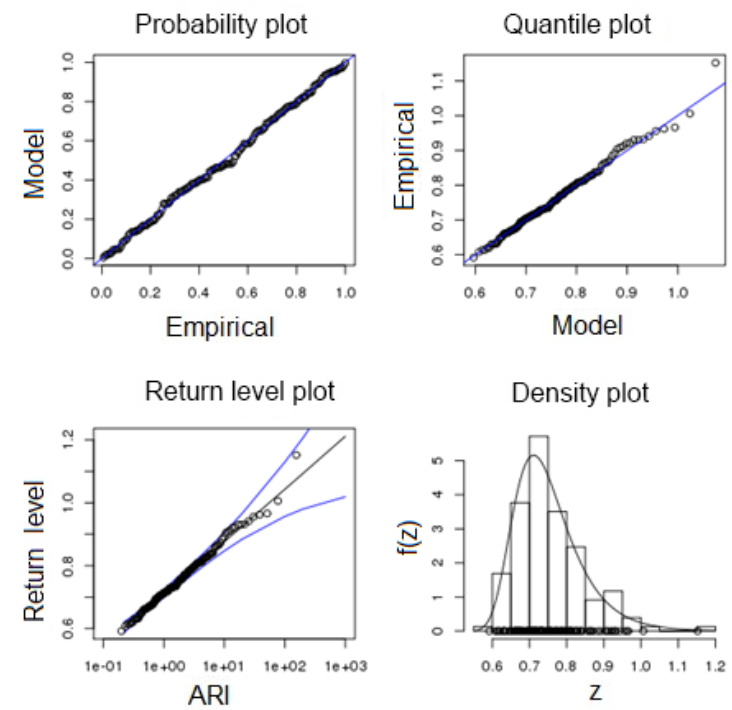

(d) GFDL
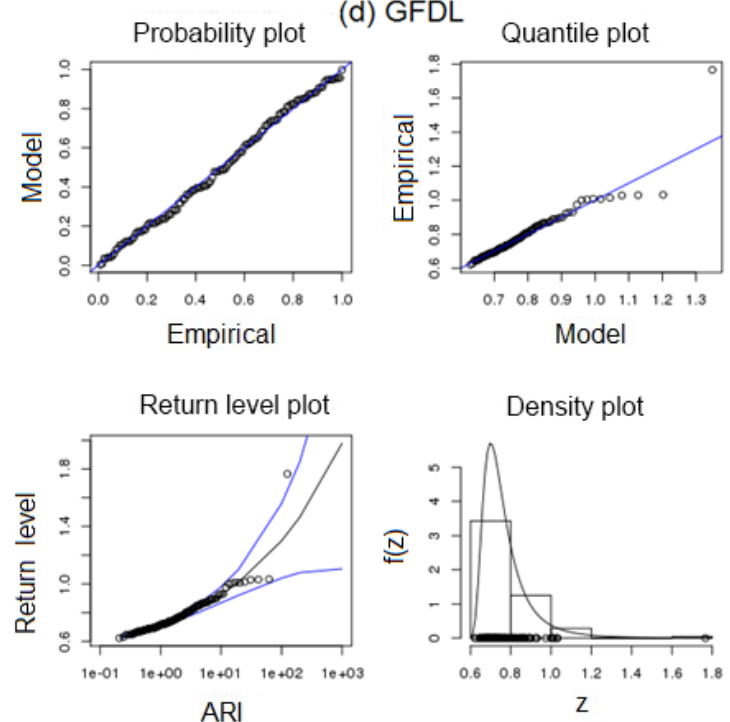

Figure A3. Standard diagnostic plots for stationary fit to significant wave height annual maxima from (a) HadGEM2-ES, (b) IPSL, (c) CNRM and (d) GFDL simulations. The quantile and probability plots compare the theoretical distribution fitted to the data with the actual data and give an indication of confidence in the fit of the return period. 
Acknowledgements. This study was carried out as part of Singapore's Second National Climate Change Study and was funded by the government of Singapore. Full reports of the study can be found of the Centre for Climate Research Singapore (CCRS) website at http://ccrs.weather.gov.sg/publications-second-National-Climate.

Jamie Kettleborough and Ian Edmond provided scripts for downloading and archiving the CMIP5 data used in this study. We thank Aimée Slangen for providing spatial fingerprint data used in the projections of regional sea level change and Mark Carson for assistance with carrying out the comparison with the Slangen et al. (2014) oceanographic sea level changes. We acknowledge use of the MONSooN system, a collaborative facility supplied under the Joint Weather and Climate Research Programme, which is a strategic partnership between the Met Office and the Natural Environment Research Council. This work also used the ARCHER UK National Supercomputing Service (http://www.archer.ac.uk).

Edited by: M. Hecht

\section{References}

Allen, J. I., Aiken, J., Anderson, T. R., Buitenhuis, E., Cornell, S., Geider, R., Haines, K., Hirata, T., Holt, J., Le Quéré, C., Hardman-Mountford, N., Ross, O. N., Sinha, B., and While, J.: Marine ecosystem models for earth systems applications: the MarQUEST experience, J. Marine Syst., 81, 19-33, 2010.

Atlas, R., Hoffman, R. N., Ardizzone, J., Leidner, S. M., Jusem, J. C., Smith, D. K., and Gombos, D.: A cross-calibrated, multiplatform ocean surface wind velocity product for meteorological and oceanographic applications, B. Am. Meteorol. Soc., 92, 157174, doi:10.1175/2010BAMS2946.1, 2011.

Batstone, C., Lawless, M., Tawn, J., Horsburgh, K., Blackman, D., McMillan, A., Worth, D., Laeger, S., and Hunt, T.: A UK best-practice approach for extreme sea-level analysis along complex topographic coastlines, Ocean Eng., 71, 28-39, 10.1016/j.oceaneng.2013.02.003, 2013.

Bidlot, J. R. and Holt, M. W.: Verification of operational global and regional wave forecasting systems against measurements from moored buoys, JCOMM Technical Report, 30, WMO/TD no. 1333, 2006.

Bidlot, J. R., Holmes-Bell, D. J., Wittmann, P. A., Lalbeharry, R., and Chen, H. S.: Intercomparison of the performance of operational ocean wave forecasting systems with buoy data, European Centre for Medium-Range Weather Forecasts (ECMWF) Technical Memorandum Number 315 also 2002, Weather Forecast., 17, 287-310, 2000.

Bidlot, J. R., Li, L. G., Wittmann, P., Fauchon, M., Chen, H., Lefevre, J. M., Bruns, T., Greenslade, D., Ardhuin, F., Kohno, N., Park, S., and Gomez, M.: Inter-comparison of operational wave forecasting systems, 10th International Workshop on Wave Hindcasting and Forecasting and Coastal Hazard Symposium, North Shore, Oahu, Hawaii, 11-16 November 2007.

Bindoff, N. L., Willebrand, J., Artale, V., Cazenave, A., Gregory, J., Gulev, S., Hanawa, K., Le Quéré, C., Levitus, S., Nojiri, Y., Shum, C. K., Talley, L. D., and Unnikrishnan, A.: Observations: Oceanic Climate Change and Sea Level, in: Climate Change 2007: The Physical Science Basis, Contribution of Working Group I to the Fourth Assessment Report of the Intergovern- mental Panel on Climate Change, edited by: Solomon, S., Qin, D., Manning, M., Chen, Z., Marquis, M., Averyt, K. B., Tignor, M., and Miller, H. L., Cambridge University Press, Cambridge, United Kingdom and New York, NY, USA, 2007.

Bird, M. I., Austin, W. E. N., Wurster, C. M., Fifield, L. K., Mojtahis, M., and Sargeant, C.: Punctuated eustatic sealevel rise in the early mid-Holocene, Geology, 38, 803-806, doi:10.1130/G31066.1, 2010.

Church, J. A., Clark, P. U., Cazenave, A., Gregory, J. M., Jevrejeva, S., Levermann, A., Merrifield, M. A., Milne, G. A., Nerem, R. S., Nunn, P. D., Payne, A. J., Pfeffer, W. T., Stammer, D., and Unnikrishnan, A. S.: Sea Level Change, in: Climate Change 2013: The Physical Science Basis, Contribution of Working Group I to the Fifth Assessment Report of the Intergovernmental Panel on Climate Change, edited by: Stocker, T. F., Qin, D., Plattner, G. K., Tignor, M., Allen, S. K., Boschung, J., Nauels, A., Xia, Y., Bex, V., and Midgley, P. M., Cambridge University Press, Cambridge, United Kingdom and New York, NY, USA, 2013.

Coles, S.: An introduction to statistical modeling of extreme values, 208 pp., London, Springer, 2001.

Dee, D. P., Uppala, S. M., Simmons, A. J., Berrisford, P., Poli, P., Kobayashi, S., Andrae, U., Balmaseda, M. A., Balsamo, G., Bauer, P., Bechtold, P., Beljaars, A. C. M., van de Berg, L., Bidlot, J., Bormann, N., Delsol, C, Dragani, R., Fuentes, M., Geer, A. J., Haimberger, L., Healy, S. B., Hersbach, H., Hólm, E. V., Isaksen, L., Kållberg, P., Köhler, M., Matricardi, M., McNally, A. P., Monge-Sanz, B. M., Morcrette, J. J., Park, B. K., Peubey, C., de Rosnay, P., Tavolato, C., Thépaut, J. N., and Vitart, F.: The ERA-Interim reanalysis: configuration and performance of the data assimilation system, Q. J. Roy. Meteor. Soc., 137, 553-597, doi:10.1002/qj.828, 2011.

de Vries, H., Breton, M., de Mulder, T., Krestenitis, Y., Ozer, J., Proctor, R., Ruddick, K., Saloman, J. C., and Voorrips, A.: A comparison of 2-D storm-surge models applied to three shallow European seas, Environ. Softw., 10, 23-42, 1995.

Hinkel, J., Jaeger, C., Nicholls, R. J., Lowe, J., Renn, O., and Peijun, S.: Sea-level rise scenarios and coastal risk management, Nature Climate Change, 5, 188-190, doi:10.1038/nclimate2505, 2015.

Horsburgh, K. J. and Wilson, C.: Tide-surge interaction and its role in the distribution of surge residuals in the North Sea, J. Geophys. Res., 112, C08003, doi:10.1029/2006JC004033, 2007.

Hosking, J. R. M., Wallis, J. R., and Wood, E. F.: Estimation of the generalized extreme-value distribution by the method of probability-weighted moments, Technometrics, 27, 251-261, 1985.

Howard, T., Lowe, J., and Horsburgh, K.: Interpreting century-scale changes in southern North Sea storm surge climate derived from coupled model simulations, J. Climate, 23, 6234-6247, 2010.

Howard, T., Pardaens, A. K., Bamber, J. L., Ridley, J., Spada, G., Hurkmans, R. T. W. L., Lowe, J. A., and Vaughan, D.: Sources of 21 st century regional sea-level rise along the coast of northwest Europe, Ocean Sci., 10, 473-483, doi:10.5194/os-10-473-2014, 2014.

Huerta, G. and Bruno, S.: Time-varying models for extreme values, Environ. Ecol. Stat., 14, 285-299, 2007.

IPCC: AR4 Climate change 2007, The physical science basis, Summary for policymakers, in: Contribution of Working Group I to the Fourth Assessment Report of the Intergovernmental Panel on Climate Change, edited by: Solomon, S., Qin, D., Manning, M., 
Chen, Z., Marquis, M., Averyt, K. B., Tignor, M., and Miller, H. L., 2007.

Jevrejeva, S., Grinsted, A., and Moore, C. J.: Upper limit for sea level projections by 2100, Environ. Res. Lett., 9, 1-9, 2014.

Kotz, S. and Nadarajah, S.: Extreme Value Distributions: Theory and Applications, London, Imperial College Press, 2000.

Kopp, R. E., Horton, R. M., Little, C. M., Mitrovica, J. X., Oppenheimer, M., Rasmussen, D. J., Strauss, B. H., and Tebaldi, C.: Probabilistic 21st and 22nd century sea-level projections at a global network of tide-gauge sites, Earth's future, 2, 383-406, 2014

Lowe, J. A., Gregory, J., and Flather, R.: Changes in the occurrence of storm surges around the United Kingdom under a future climate scenario using a dynamic storm surge model driven by the Hadley Centre climate models, Clim. Dynam., 18, 179-188, 2001.

Lowe, J. A., Howard, T. P., Pardaens, A., Tinker, J., Holt, J., Wakelin, S., Milne, G., Leake, J., Wolf, J., Horsburgh, K., Reeder, T., Jenkins, G., Ridley, J., Dye, S., and Bradley, S.: UK Climate Projections science report: Marine and coastal projections, Met Office Hadley Centre, Exeter, UK, 2009.

Madec, G.: NEMO reference manual 3/4 Stable: NEMO ocean engine, Note du Pôle de modélisation, Institut Pierre-Simon Laplace (IPSL), France, 27, 1288-1619, 2008.

Maren, D. V. and Gerritsen, H.: Residual flow and tidal asymmetry in the Singapore Strait, with implications for resuspension and residual transport of sediment, J. Geophys. Res., 117, C04021, doi:10.1029/2011JC007615, 2012.

McSweeney, C., Rahmat, R., Redmond, G., Marzin, C., Murphy, J., Jones, R., Cheong, W. K., Lim, S. Y., and Sun, X.: Singapore's Second National Climate Change Study - Phase 1, Chapter 3, Sub-selection of CMIP5 GCMs for downscaling over Singapore, available at: http://ccrs.weather.gov.sg/publicationssecond-National, last access: 28 Oktober 2015.

McSweeney, C. F., Jones, R. G., Lee, R. W., and Rowell, D. P.: Selecting CMIP5 GCMs for downscaling over multiple regions, Clim. Dynam., 44, 3237-3260, 2015.

Méndez, F. J., Menéndez, M., Luceño, A., and ILosada, I. J.: Analyzing Monthly Extreme Sea Levels with a TimeDependent GEV Model, J. Atmos. Ocean. Technol., 24, 894911, doi:10.1175/JTECH2009.1, 2007.

Mendez, F. J., Menendez, M., Luceo, A., and Losada, I. J.: Estimation of the long-term variability of extreme significant wave height using a time-dependent Peak Over Threshold (POT) model, J. Geophys. Res., 111, C07024, doi:10.1029/2005JC003344, 2008.

Meinshausen, M., Smith, S. J., Calvin, K. V., Daniel, J. S., Kainuma, M. L. T., Lamarque, J. F., Matsumoto, K, Montzka, S. A., Raper, S. C. B., Riahi, K., Thomson, A. M., Velders, G. J. M., and van Vuuren, D.: The RCP Greenhouse Gas Concentrations and their Extension from 1765 to 2300, Climatic Change, 109, 213-241, doi:10.1007/s10584-011-0156-z, 2011.

Monbaliu, J., Padilla-Hernandez, R., Hargreaves, J. C., Albiach, J. C. C., Luo, W., Sclavo, M., and Gunther, H: The spectral wave model, WAM, adapted for applications with high spatial resolution, Coast. Eng., 41, 41-62, 2000

Mousavi, M., Irish, J., Frey, A., Olivera, F., and Edge., B: Global warming and hurricanes: The potential impact of hurricane inten- sification and sea level rise on coastal flooding, Climatic Change, 104, 575-597, 2011.

Pardaens, A., Gregory, J. M., and Lowe, J.: A model study of factors influencing projected changes in regional sea level over the twenty-first century, Clim. Dynam., 36, 2015-2033, 2011.

Pawlowicz, R., Beardsley, B., and Lentz, S.: Classical Tidal Harmonic Analysis Including Error Estimates in MATLAB using TTIDE, Comput. Geosci., 28, 929-937, 2002.

Peltier, W. R.: Global Glacial Isostasy and the Surface of the IceAge Earth: The ICE-5G (VM2) Model and GRACE, Annu. Rev. Earth Planet. Sci., 32, 111-149, 2004.

Penduff, T., Juza, M., Brodeau, L., Smith, G. C., Barnier, B., Molines, J.-M., Treguier, A.-M., and Madec, G.: Impact of global ocean model resolution on sea-level variability with emphasis on interannual time scales, Ocean Sci., 6, 269-284, doi:10.5194/os6-269-2010, 2010.

Perrette, M., Landerer, F., Riva, R., Frieler, K., and Meinshausen, M.: A scaling approach to project regional sea level rise and its uncertainties, Earth Syst. Dynam., 4, 11-29, doi:10.5194/esd-411-2013, 2013.

Pickering, M.: The impact of future sea-level rise on the tides, University of Southampton, Ocean and Earth Science, Doctoral Thesis, 347 pp., 2014.

Slangen, A. B. A., Carson, M., Katsman, C. A., van de Wal, R. S. W., Koehl, A., Vermeersen, L. L. A., and Stammer, D.: Projecting twenty-first century regional sea-level changes, Climatic Change, 124, 317-332, doi:10.1007/s10584-014-1080-9, 2014.

Smith, J. M., Cialone, M. A., Wamsley, T. V., and McAlpin, T. O.: Potential impact of sea level rise on coastal surges in southeast Louisiana, Ocean Eng., 37, 37-47, 2010.

Sterl, A., van den Brink, H., de Vries, H., Haarsma, R., and van Meijgaard, E.: An ensemble study of extreme storm surge related water levels in the North Sea in a changing climate, Ocean Sci., 5, 369-378, doi:10.5194/os-5-369-2009, 2009.

Tamisiea, M. E. and Mitrovica, J. X.: The moving boundaries of sea level change: Understanding the origins of geographic variability, Oceanography, 24, 24-39, doi:10.5670/oceanog.2011.25, 2011.

Tamisiea, M. E., Hughes, C. W., Williams, S. D. P., and Bingley, R. M.: Sea level: measuring the bounding surfaces of the ocean, Philos. T. R. Soc. A, 372, 1-26, doi:10.1098/rsta.2013.0336, 2014.

Tkalich, P., Vethamony, P., Babu, M. T., and Pokratath, R.: Seasonal sea level variability and anomalies in the Singapore Strait, Proceedings of International Conference in Ocean Eng., ICOE 2009 IIT Madras, Chennai, India, 10-5 February 2009.

Tkalich, P., Vethamony, P., Luu, Q.-H., and Babu, M. T.: Sea level trend and variability in the Singapore Strait, Ocean Sci., 9, 293 300, doi:10.5194/os-9-293-2013, 2013.

Tolman, H. L.: User manual and system documentation of WAVEWATCH-III version 1.15 , NOAA/NWS/NCEP/OMB Technical Note 151, 97 pp., 1997.

Tolman, H. L.: User manual and system documentation of WAVEWATCH-III version 1.18, NOAA/NWS/NCEP/OMB Technical Note 166, 110 pp., 1999.

Tolman, H. L.: User manual and system documentation of WAVEWATCH III version 3.14, NOAA/NWS/NCEP/MMAB Technical Note 276, 194 pp., 2009.

Tolman, H. L. and Chalikov, D. V.: Source terms in a 3rd generation wind-wave model, J. Phys. Oceaonogr., 26, 2497-2518, 1996. 
Wilby, R. L., Troni, J., Biot, Y., Tedd, L., Hewitson, B. C., Smith, D. M., and Sutton, R. T.: A review of climate risk information for adaptation and development planning, Int. J. Climatol., 29, 1193-1215, 2009.

Whetton, P., Hennessy, K., Clarke, J., McInnes, K., and Kent, K.: Use of Representative Climate Futures in impact and adaptation assessment, Climatic Change, 115, 433-442, 2012.
Wong, P. P.: Impact of a sea level rise on the coasts of Singapore: preliminary observations, J. Southe. Asian Earth, 7, 65-70, 1992. 